\title{
A new parrot taxon from the Yucatán Peninsula, Mexico - its position within genus Amazona based on morphology and molecular phylogeny
}

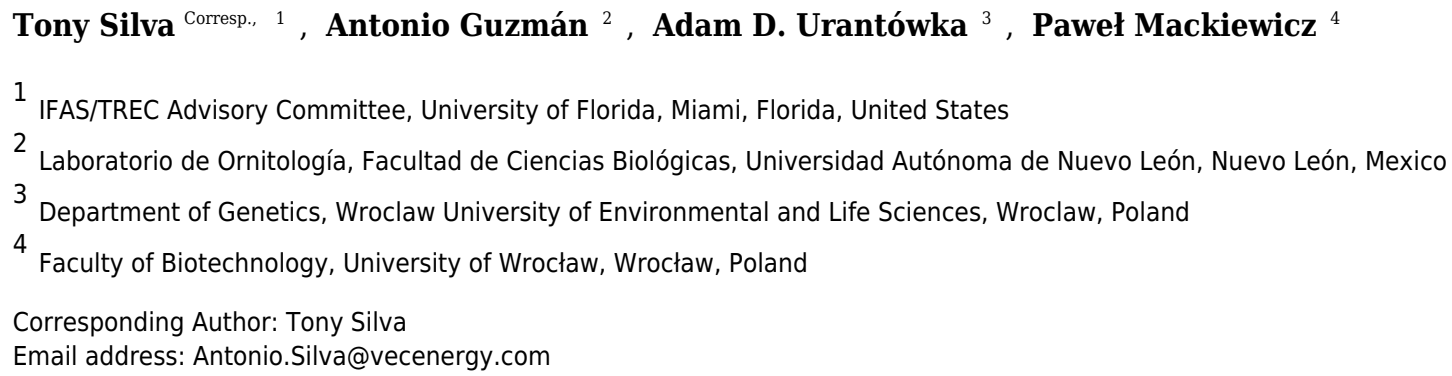

Parrots (Psittaciformes) are a diverse group of birds, which need urgent protection. However, many taxa from this order have an unresolved status, which makes their conservation difficult. One species-rich parrot genus is Amazona, which is widely distributed in the New World. Here we describe a new Amazona form, which is endemic to the Yucatán Peninsula. This parrot is clearly separable from other Amazona species in eleven morphometric characters as well as call and behavior. The clear differences in these features imply that the parrot most likely represents a new species. In contrast to this, the phylogenetic tree based on mitochondrial markers shows that this parrot groups with strong support within $A$. albifrons from Central America, which would suggest that it is a subspecies of $A$. albifrons. However, taken together tree topology tests and morphometric analyses, we can conclude that the new parrot represents a recently evolving species, whose taxonomic status should be further confirmed. This lineage diverged from its closest relative about 120,000 years ago and was subjected to accelerated morphological and behavioral changes like some other representatives of the genus Amazona. Our phylogenies, which are so far the most comprehensive for Amazona taxa enabled us to consider the most feasible scenarios about parrot colonization of the Greater and Lesser Antilles and Central America from South America mainland. The molecular dating of these migrations and diversification rate were correlated with climatic and geological events in the last 5 million years giving an interesting insight into Amazon parrot phylogeography and their evolution in general. 
1 A new parrot taxon from the Yucatán Peninsula, Mexico - its

\section{position within genus Amazona based on morphology and molecular phylogeny}

4 Tony Silva ${ }^{1 *}$, Antonio Guzmán $^{2}$, Adam Urantówka $^{3}$, Paweł Mackiewicz ${ }^{4}$

5

$6{ }^{1}$ IFAS/TREC Advisory Committee, University of Florida, 23605 SW 217 Ave, Miami, Florida,

7 33031, United States of America

$8{ }^{2}$ Laboratorio de Ornitología, Facultad de Ciencias Biológicas, Universidad Autónoma de Nuevo

9 León, San Nicolás de los Garza, Nuevo León, 66451, México

$10{ }^{3}$ Department of Genetics, Wroclaw University of Environmental and Life Sciences, $u l$.

11 Kożuchowska 7, Wroclaw 51-631, Poland

$12{ }^{4}$ Faculty of Biotechnology, University of Wrocław, ul. Fryderyka Joliot-Curie 14a, 50-383

13 Wrocław, Poland

$14 *$ Corresponding author

15 E-mail: Antonio.Silva@vecenergy.com 


\section{Abstract}

17 Parrots (Psittaciformes) are a diverse group of birds, which need urgent protection. However, 18 many taxa from this order have an unresolved status, which makes their conservation difficult. 19 One species-rich parrot genus is Amazona, which is widely distributed in the New World. Here 20 we describe a new Amazona form, which is endemic to the Yucatán Peninsula. This parrot is 21 clearly separable from other Amazona species in eleven morphometric characters as well as call 22 and behavior. The clear differences in these features imply that the parrot most likely represents a 23 new species. In contrast to this, the phylogenetic tree based on mitochondrial markers shows that 24 this parrot groups with strong support within A. albifrons from Central America, which would 25 suggest that it is a subspecies of A. albifrons. However, taken together tree topology tests and 26 morphometric analyses, we can conclude that the new parrot represents a recently evolving 27 species, whose taxonomic status should be further confirmed. This lineage diverged from its 28 closest relative about 120,000 years ago and was subjected to accelerated morphological and 29 behavioral changes like some other representatives of the genus Amazona. Our phylogenies, 30 which are so far the most comprehensive for Amazona taxa enabled us to consider the most 31 feasible scenarios about parrot colonization of the Greater and Lesser Antilles and Central 32 America from South America mainland. The molecular dating of these migrations and 33 diversification rate were correlated with climatic and geological events in the last 5 million years 34 giving an interesting insight into Amazon parrot phylogeography and their evolution in general. 
35

36

37 38

\section{Introduction}
1.1 .
The genus Amazona and its taxonomic changes

Amazona (Amazon parrots) is the most species-rich genus within the Androglossini tribe (Schodde et al. 2013). The Amazon parrots are strictly neotropical with a distribution that extends from northern Mexico through Mesoamerica and the Caribbean to much of South America, with the southernmost distribution reaching the provinces of Santa Fé and Córdoba in Argentina (Darrieu 1983). They are characterized by medium to large size, strong-heavy bill, short-rounded tail, prominent naked cere and a distinct notch in the upper mandible (Forshaw 1973; Juniper \& Parr 1998). Their body plumage is predominantly green with variable colorations on the head, breast, shoulders, and/or flight feathers. Red, yellow, white and blue are dominating colors in their head. The tail is squared in shape and often banded with red and blue stripes. The variation of these accenting colors is one of the morphological features commonly used to distinguish the species and subspecies. However, phylogenetic analyses of mitochondrial DNA (mtDNA) have not always supported the current classification of the Amazona group (Eberhard \& Bermingham 2004).

When Forshaw published the first edition of his Parrots of the World (Forshaw 1973), the genus Amazona contained 27 species. No one refuted this arrangement until 1981, when the species number increased to 28 with the elevation of $A$. rhodocorytha to species status (Barrowclough et al. 2016); it was formerly regarded as a subspecies of A. dufresniana (Forshaw 1973). The first substantial change in the taxonomy of this genus was the transfer of Amazona xanthops to the new genus Alipiopsitta (Caparroz \& Pacheco 2006; Duarte \& Caparroz 1995), whose distinctness was first noted by the senior author (Silva 1991). These results opened the floodgates for a series of partial (Eberhard \& Bermingham 2004; Ribas et al. 2007; Silva 2014; Urantowka et al. 2014) or complete revisions of the genus Amazona (Russello \& Amato 2004). Many of these changes have elevated Amazona subspecies to the species rank, as in the case of $A$. oratrix and $A$. auropalliata (Clements et al. 2016; Gill \& Donsker 2017), and four new Amazona subspecies have been named (Lousada 1989; Lousada \& Howell 1997; Reynolds \& Hayes 2009).

While the taxonomic changes were ongoing (H. Sick in litt. to T. Silva, 1988), an additional new species, A. kawallii, was described (Grantsau \& Camargo 1989). Its validity was firstly questioned (Vuilleumier et al. 1992) but reaffirmed soon afterwards by other authors (Collar \& Pittman 1996; Martuscelli \& Yamashita 1997; Silva 2015). Currently, most of the present checklists assume that the genus Amazona contains 30 species, e.g. Clements et al. (2016). 
67 1.2. Amazona species native to Mexico and finding the new dimorphic Amazona

68 Mexico is the home of 23 parrot species of which six are endemic (Gómez Garza 2014; Herminio 69 Plasencia-Vazquez \& Escalona-Segura 2014; Juniper \& Parr 1998). Eight of these species belong 70 to the genus Amazona and two of them (Amazona viridigenalis and A. finschi) are found only in 71 Mexico. The Mexican Amazon parrots can be divided into three groups with different coloring: 72 1) having variable amounts of yellow on the head (A. oratrix, A. auropalliata); 2) predominately 73 green with only blue on the head (A. farinosa guatemalae); and 3) possessing various tonalities of 74 red in the head invariably accompanied by blue (Amazona viridigenalis, A. finschi), yellow 75 (Amazona xantholora, A. autumnalis) or white (Amazona xantholora, A. albifrons). 76 Monomorphism is the rule in the genus Amazona. However, two species, Amazona albifrons (all 77 three subspecies) and Amazona xantholora, display significant dimorphism: males possess much 78 more colorful heads and a more extensively red colored alula and wing speculum (Gómez Garza 79 2014; Silva 1991).

80 In the beginning of 2014, during a visit to a remote part of the Yucatán Peninsula, in south of 81 Becanchén in Tekax Municipality (Fig. 1), Miguel A. Gómez Garza sighted parrots with 82 coloration completely different from that of other known species. The birds' appearance and 83 behavior suggested that they belong to the genus Amazona. The individuals of this unknown 84 taxon also exhibited sexual dimorphism (Fig. 2 and Fig. 3) like the sympatric Amazona albifrons 85 and Amazona xantholora.

86 To verify the taxonomic status of the new parrot, we performed a detailed morphological study 87 comparing it with other Mexican Amazona species that possess red feathers in the head. 88 Moreover, to establish its phylogenetic position within the genus Amazona, we also sequenced 89 three typical mitochondrial markers from the new form and also from Amazona xantholora, 90 which had not been previously studied at the molecular level.

91 This new parrot can be confused with A. albifrons and A. xantholora in the field when observed 92 at a distance, by their similar size and general appearance. However, its call and other 93 morphological features are very distinctive and could be used in discrimination of this parrot as a 94 new species, at least under typological, morphological and phenetic species concepts. On the 95 other hand, molecular phylogenetic analyses imply that this parrot could be a subspecies of $A$. 96 albifrons. Therefore, we discussed the pros and cons of these two taxonomic concepts and 
97 presented its phylogenetic position in the wide framework of genus Amazona evolution and 98 phylogeography.

101 Living specimens of known morphological types of both sexes (male holotype and female 102 paratype - see Fig. 4-7) of the new Amazona were collected in the Yucatán Peninsula in Mexico, 103 south of Becanchén in Tekax Municipality. However, the detailed location is not provided here

104 due to conservation reasons. Both individuals are now maintained as living birds in Mexico by 105 Miguel Angel Gómez Garza with the permission and authorization of the Procuraduría Federal de 106 Protección al Ambiente (PROFEPA), the national wildlife protection agency. Tail feathers from 107 both specimens were used for DNA isolation and were also deposited in the collection of the 108 Laboratorio de Ornitología, Facultad de Ciencias Biológicas, Universidad Autonóma de Nuevo 109 León, Mexico. This material is assigned the following catalog numbers: MGG01-Amazona 110 gomezgarzai-Holotipo- for male feathers and MGG02-Amazona gomezgarzai-Alotipo- for female

111 feathers. Both the living holotype and paratype will be ceded with the authorization of PROFEPA 112 to the Laboratorio de Ornitología, Facultad de Ciencias Biológicas, Universidad Autonóma de 113 Nuevo León, Mexico, upon their death.

114 We checked the collections of six museums rich in Mexican birds for possibly misidentified 115 specimens of the new taxon that could have been used as type specimens: Museo Nacional de 116 Historia Natural in Madrid (Spain), the collection belonging to the Estación Biológica de Doñana 117 in Seville (Spain), the Field Museum of Natural History in Chicago (USA), Museo de las Aves de 118 México in Saltillo (Mexico), Laboratorio de Ornitología, Universidad Autónoma de Nuevo León 119 (Mexico) and the Laboratorio de Ornitología de la Universidad Nacional Autónoma de México 120 (Mexico). However, we did not find any specimens with characteristics of the new taxon.

121 The electronic version of this article in Portable Document Format (PDF) will represent a 122 published work according to the International Commission on Zoological Nomenclature (ICZN), 123 and hence the new names contained in the electronic version are effectively published under that 124 Code from the electronic edition alone. This published work and the nomenclatural acts it 125 contains have been registered in ZooBank, the online registration system for the ICZN. The 126 ZooBank LSIDs (Life Science Identifiers) can be resolved and the associated information viewed 127 through any standard web browser by appending the LSID to the prefix http://zoobank.org/. The 128 LSID for this publication is urn:lsid:zoobank.org:act:C4AA8659-8077-4195-9E11- 
129 D2EB3635397C. The online version of this work is archived and available from the following

130 digital repositories: PeerJ, PubMed Central and CLOCKSS.

131 In taxonomic circles, there has been much debate about the deposition of preserved voucher 132 specimens when naming a species (Donegan 2008; Dubois \& Nemésio 2007; Nemesio 2009). In

133 the current case, the precarious status of the new Amazona, which warrants a listing of Critically

134 Endangered (CR) under IUCN (International Union for the Conservation of Nature) criteria 135 makes the collection of a preserved specimen ethically impossible; the taking of two living 136 specimens will permit their nesting biology in captivity to be studied, as the birds are held in a 137 manner that should allow them to breed; when such breeding takes place, details on incubation 138 and the development of the young can be documented.

139 A precedent for naming species without the formal deposition of such type was proposed by 140 Smith et al. (1991) and was followed by others (Athreya 2006; Gentile \& Snell 2009; Jones et al. 141 2005). Three former secretaries of the International Commission on Zoological Nomenclature 142 support the view that the CODE allows the naming of a species without the collection of a 143 voucher specimen in particular circumstances, see Polaszek et al. (2005) and Wakeham-Dawson 144 et al. (2002). Moreover, Article 16.4.2 of the CODE states that where the holotype is an extant 145 individual, a statement of the intent to deposit the individual in a collection upon its death 146 accompanied by a statement indicating the name and location of that collection is sufficient.

147 Herein, the authors follow Böhme \& Ziegler (1997) in naming a new species based on a living 148 specimen, but the recommendation by Dubois (2009), who suggested that museums be contacted 149 for the existence of specimens that had not erstwhile been recognized, was followed to no avail 150 for the new Amazona. In lieu of an onomatophore specimen of the new parrot, the authors 151 deposited feathers from the holotype and paratype as vouchers in following Smith et al. (1991), 152 per the recommendation of Donegan (2008) and in compliance with Article 72.5.1 of the CODE, 153 which states that a type may be an animal or any part of an animal. Article 16.4.2 of the CODE 154 will be met with the deposition in a secure collection of the extant, caged individuals from whom 155 the feathers were removed upon their death. The photographs and illustrations that accompany 156 this description represent the designated holotype and paratype. The authors thus believe that 157 they have met all thresholds to adequately name for the new Amazona taxon. 
159 Adult specimens of parrots were collected evenly throughout the whole year without focusing on 160 a specific season. We observed no great variation of weights between individuals of the same 161 species. We examined them according to five metric features: body weight, total length, length of 162 wing chord, tail length and exposed culmen, as well as six morphological discrete characters: 163 coloration of forehead, lores, cheeks and crown, the presence of black ear patch and black 164 scalloping on contour feathers on the face (Table 1, 2 and 3). The measurements were taken by 165 one person (TS) using Fischer Scientific digital caliper with the resolution of $0.1 \mathrm{~mm}$. Three 166 individuals of each sex were measured for each taxon, except for Amazona autumnalis in which 167 six birds of unknown sex were taken into account. In the case of the new Amazona, only two 168 specimens were collected and analyzed in details because of its endangered status but several 169 small groups with up to 12 individuals were additionally observed and studied in the field. To use 170 the different morphometric features simultaneously in multivariate studies, we normalized their 171 values using the minimum-maximum method: (value-min)/(max-min). The metric features were 172 first averaged per the particular taxon or sex before the normalization. The morphological 173 discrete characters were coded as 1 (when the character was present), 0 (when it was absent) or 1740.5 (when it has an intermediate state).

175 The Principal Component Analysis (PCA) was done using the Statistica software (StatSoft_Inc. 176 2011). In the analysis, covarion matrix was used on the normalized data to calculate principal 177 components. Hierarchical clustering of parrot taxa was performed on the normalized 178 morphometric features using pvclust function in R package (R_Core_Team 2015) assuming 179 Euclidean distance and UPGMA as agglomeration method. To estimate the uncertainty in the 180 clustering, AU (Approximately Unbiased) p-value and BP (Bootstrap Probability) value were 181 calculated for each cluster with bootstrap resampling assuming 1000 replications. The AU p182 value, which is computed by multiscale bootstrap resampling, is considered a better 183 approximation to unbiased p-value than the standard BP value computed by normal bootstrap 184 resampling (Shimodaira 2004).

185 High quality parrots' vocalization files were downloaded from Avian Vocalizations Center 186 (AVoCet, http://avocet.zoology.msu.edu) and xeno-canto database (http://www.xeno-canto.org): 187 AV14063 (Amazona albifrons) recorded by Pamela C. Rasmussen, AV11523 (Amazona agilis) 
188 recorded by Brian K. Schmidt, XC77749 (Amazona xantholora) recorded by Mary Beth Stowe, 189 XC282102 (Amazona albifrons) recorded by Oscar Humberto Marin-Gomez as well as XC97904 190 (Amazona agilis) and XC5942 (Amazona xantholora) both recorded by Richard C. Hoyer. The 191 files together with call records obtained for the new taxon were processed and analyzed in 192 Avisoft-SASLab 5.209 (Sound Analysis and Synthesis Laboratory) and Sound Analysis Pro 2011 193 (Tchernichovski et al. 2000), in which syllable units were identified (segmented by amplitude) 194 and their statistic features were derived. These features were next studied by Discriminant 195 Function Analysis (DFA) including Canonical analysis (CA) using the Statistica software 196 (StatSoft_Inc. 2011) as well as by non-parametric Kruskal-Wallis test and Dunn's test of post-hoc 197 multiple comparisons with Benjamini-Hochberg correction for p-values using $\mathrm{R}$ package 198 (R_Core_Team 2015).

\subsection{DNA extraction and amplification}

200 Total genomic DNA was extracted from tail feather from the living specimens of the new 201 Amazona and A. xantholora using Qiagen DNeasy® tissue extraction kits (Valencia, CA) and 202 following the manufacturer's protocol. Afterwards, amplification of sex specific $C H D-Z$ and $203 C H D-\mathrm{W}$ introns was performed for molecular sexing of the new Amazona individuals. The pair 204 of $2550 \mathrm{~F}$ and $2718 \mathrm{R}$ primers was used in PCR reactions according to the protocol previously 205 described by Fridolfsson and Ellegren (Fridolfsson \& Ellegren 1999). Obtained amplicons were 206 analyzed with the Agilent 2200 TapeStation System (Fig. S1).

207 Three mitochondrial genes, COI, 12S and 16S rRNA, were amplified using the previously 208 published protocol described by Russello \& Amato (2004). PCR products were purified and 209 sequenced in both directions at the sequencing service Macrogen ${ }^{\circledR}$ (Rockville, MD). Full 210 complementary strands of each gene were unambiguously aligned using CodonCode Aligner

211 (CodonCode Corporation ${ }^{\circledR}$, Dedham, MA). The newly obtained sequences are available in 212 GenBank database under accession numbers: KU605663-8.

\section{2.4. Phylogenetic analyses}

214 The obtained new mitochondrial sequences were aligned with all corresponding sequences of 215 Amazona taxa available in GenBank, including Pionus menstruus as an outgroup (Table S1). 216 Most of the sequences were obtained by Russello \& Amato (2004) and one by Eberhard \& 
217 Wright (2016). In their papers is provided further information about geographic origin and 218 vouchers for them. The final alignment used in phylogenetic studies comprised 45 sequences 219 with the length of $1485 \mathrm{bp}$ including three markers: 12S rRNA (390bp), 16S rRNA (534bp) and 220 COI (561bp).

221 For reconstructing phylogenetic trees, we applied four algorithms: Bayesian inference in 222 MrBayes 3.2.3 (Ronquist et al. 2012), PhloBayes MPI 1.5 (Lartillot et al. 2013) and Beast 2.4.0 223 (Bouckaert et al. 2014), as well as maximum likelihood (ML) analyses in TreeFinder (Jobb et al. 224 2004) and RAxML 8.2.3 (Stamatakis 2014). The best-fit partitioning schemes were selected 225 according to PartitionFinder 1.1.1 based on BIC criterion (Lanfear et al. 2012) - Table S2. In 226 TreeFinder, we also applied these partitioning scheme using models suggested by TreeFinder 227 Propose Model module based on BIC for these partitions. Moreover, to specify appropriate 228 substitution models across the larger space in the Bayesian MCMC analysis (Huelsenbeck et al. 229 2004), we used mixed models in MrBayes analysis.

230 In the MrBayes analysis, two independent runs starting from random trees were applied, each 231 using 4 Markov chains. Trees were sampled every 100 generations for 10,000,000 generations. In 232 the final analysis, we selected trees from the last 4,082,000 generations that reached the 233 stationary phase and convergence (i.e. the standard deviation of split frequencies stabilized and 234 was lower than the proposed threshold of 0.01). In PhyloBayes, we used CAT-GTR model with 235 rate variation across sites modeled by five discrete rate categories of gamma distribution. The 236 number of components, weights and profiles of the model were inferred from the data. Two 237 independent Markov chains were run for 100,000 generations in each of these analyses. The last 23885,000 trees from each chain were collected to compute posterior consensus trees after reaching 239 convergence, when the largest discrepancy observed across all bipartitions (maxdiff) was below 240 recommended 0.1. We set search depth to 2 in TreeFinder and applied 1000 distinct ML searches 241 on 1000 randomized stepwise addition parsimony trees in RAxML. To assess significance of 242 particular branches, non-parametric bootstrap analyses were performed on 1000 replicates in 243 these two programs.

244 Tree topologies assuming different relationships between parrots from the Greater Antilles and 245 Central America as well as the alternative position of the newly described Amazona were 246 compared according to approximately unbiased (AU), Shimodaira-Hasegawa (SH) and weighted 247 Shimodaira-Hasegawa (wSH) tests, which were performed in Consel v0.20 (Shimodaira \& 
248 Hasegawa 2001) assuming 10,000,000 replicates. Site-wise log-likelihoods for the analyzed trees

249 were calculated in TreeFinder under the best fitted substitution models.

250 Divergence times were estimated with Beast software. As constraints for tree calibration, we 251 assumed the uniform prior distribution of the separation time between Pionus menstruus and 252 Amazona dated from 5.646 to 16.553 million years ago, and the divergence time of $A$. aestiva, A. 253 dufresniana and $A$. pretrei as dating from 2.877 to 10.502 million years ago, according to 254 Schweizer et al. (2011). We tested both strict and lognormal relaxed clock models assuming the 255 calibrated Yule model and separate substitution schemes for particular data partitions according to 256 PartitionFinder results (Table S2). Finally, we applied the relaxed clock model for the second 257 codon position and the strict clock model for rRNA genes as well as the first and third codon 258 positions. The decision about the selection of clock model was made based on the inspection of 259 the standard deviation of the relaxed clock assuming that its value exceeding 1 indicates a 260 significant variation among branches. The clock and substitution rates were estimated in the 261 analyses. Posterior distributions of parameters were estimated for 100,000,000 generations with a 262 sampling frequency of 1000 steps. The convergence and sufficient sampling was checked using 263 Tracer 1.6 (Rambaut et al. 2014). Effective sample size (ESS) for all parameters was larger than 264 the assumed threshold 200, which indicated sufficient convergence, sampling and chain mixing. 265 Phylogenetic trees were summarized in TreeAnnotator 2.3.1 (Drummond et al. 2012) with 10\% 266 burn-in of total trees using maximum clade credibility tree and common ancestor heights. The 267 generated tree was visualized in FigTree 1.4.2 (Rambaut 2012).

268 The number of base differences per site (p-distance) between selected pair of sequences was 269 calculated in MEGA6 (Tamura et al. 2013). The analysis involved all 1485 positions in the 270 alignment. The distance was expressed as percent. Standard error was estimated by bootstrap 271 method assuming 1000 replicates.

273 The maximum clade credibility tree obtained from Beast and associated branching times were 274 used for calculation diversification rate using R package LASER 2.4 (Rabosky 2006a). In order 275 to test whether diversification rates decreased with time, we calculated the $\gamma$ statistic (Pybus \& 276 Harvey 2000). We also tested 11 likelihood models for diversification rates (Rabosky 2006b; 277 Rabosky \& Lovette 2008) - Table S3. The models were compared according to the values of the 
278 Akaike information criterion (AIC). Temporal variation in diversification rates was visualized

279 with yuleWindow (Nee 2001) within overlapping periods of 400 thousand years. The results of

280 diversification were compared with the $\delta^{18} \mathrm{O}$ curve (Lisiecki \& Raymo 2005), which is a good

281 climate proxy. For better visualization of climate oscillations, we calculated the variance in the

$282 \delta^{18} \mathrm{O}$ records within the same overlapping periods.

\section{Results}

\subsection{Multivariate analyses of morphometric and vocalization features}

285 One of the most distinctive metric features that can be used to differentiate the Amazona parrots 286 from Mexico possessing red feathers in the head area are the length of the wing chord, tail and 287 exposed culmen (Table 1). To visualize these differences, we performed PCA analysis (Fig. 8). 288 The first two factor coordinates explained in total $94 \%$ of variance ( $86 \%$ and $8 \%$, respectively). 289 In the PCA plot obtained, the first component is responsible for the separation of the species, 290 whereas the second one applies to sexual dimorphism. The first component was highly correlated 291 with all three variables: wing chord (-0.90), tail (-0.96) and exposed culmen (-0.91). Generally, 292 parrots with the largest dimensions of studied characters (A. autumnalis and A. viridigenalis) are 293 located on the left of the plot, whereas parrots characterized by smaller length values ( $A$. 294 albifrons and A. xantholora) are placed on the right. The new Amazona with the intermediate 295 length of the wing chord, tail and exposed culmen occurs between these two extremes. The 296 second component showed the highest correlation with exposed culmen (-0.42) and is responsible 297 for the separation of sexes. Males of almost all the species are located at the lower part of the plot 298 and are characterized by the larger length of exposed culmen than females, which are placed 299 above them in the plot. Only the male of $A$. a. saltuensis is placed among females of other 300 species. In fact, the difference in this parameter between A. a. saltuensis sexes is smallest. This 301 taxon shows also the shortest distance between two sexes, whereas A. viridigenalis shows the 302 largest. The latter species is also farthest from the parrots of Central America, which are grouped 303 on the right site of the plot. The individual of $A$. autumnalis without assigned sex is closest to the 304 A. viridigenalis male. The male of the new Amazona quite clearly separates from males of other 305 Mexican taxa, whereas the female of this new form is located near the A. a. saltuensis male and 306 A. xantholora female in the plot.

307 We also compared the studied parrot taxa in PCA analysis (Fig. 9) using both five metric (Table 308 1) and six morphological features (Table 2). The first two factor coordinates explained almost 
$30981 \%$ of variance ( $63 \%$ and $17 \%$, respectively). The first component showed the highest 310 correlation with metric features: the total length (-0.96), wing chord (-0.94), tail (-0.94), exposed 311 culmen (-0.94) and weight (-0.90), as well as some morphological characters: coloring of 312 forehead (0.84), the presence of black scalloping contour feathers (0.79) and coloring of cheeks 313 (0.73). The second component was highly correlated with crown coloring (0.83), coloring of the 314 lores (-0.59) and the presence of a black ear patch (0.59). The first component is responsible for 315 the distinct separation of $A$. autumnalis and A. viridigenalis from the other Mexican parrots 316 because of their larger weight and length of studied characters as well as the absence of black 317 scalloping contour feathers. The Mexican parrots are differentiated by the second component into 318 the group of $A$. albifrons subspecies and the cluster of the new Amazona and A. xantholora. The 319 outlying position of the new Amazona results from its unique green coloring of crown versus blue 320 and bluish in other parrots. In turn, A. xantholora separates because it has yellow lores and black 321 ear patch as the only species of the studied species. The three subspecies of $A$. albifrons are 322 clustered together because of white forehead and subtle black scalloping contour feathers. In 323 agreement with these results, the hierarchical clustering based on five metric parameters clearly 324 separates $A$. autumnalis and A. viridigenalis from Central America parrots (Fig. 10). At the base 325 of the latter group, A. xantholora is placed and next the new Amazona branches off. The 326 subspecies of $A$. albifrons create a significant cluster with A. albifrons nana at the base.

327 The proposed new taxon is characterized by a unique vocalization in comparison to other 328 Amazon parrots inhabiting Central America (Fig. 11, Supporting information Files S1 and S2). In 329 this comparison, we also included Amazona agilis from the Greater Antilles because it appears 330 the sister taxon to the Central American parrots (see section Molecular phylogenetic studies). The 331 most distinct feature of the new Amazona is a relatively long duration of syllables, which is 332 almost 5 times longer in comparison to $A$. albifrons and more than 3 times longer than in $A$. 333 xantholora (Fig. 11). For each of 12 considered vocalization features, the new taxon differs 334 significantly $(\mathrm{p}<0.05)$ from at least one of three other analyzed Amazona parrots (Supporting 335 information Fig. S2 and Table S4). Besides syllable duration, it is also significantly different 336 from all three parrots in mean FM (frequency modulation), mean Wiener entropy (a measure of 337 the width and uniformity of the power spectrum) and variance of mean frequency (the center of 338 gravity of the power spectrum). In total, the new Amazona differs significantly in seven features 339 from $A$. albifrons, nine from A. xantholora and ten from A. agilis. 
340 In agreement with that, Discriminant Function Analysis with Canonical Analysis shows the clear

341 separation of the four parrots according to the twelve statistical features of their syllables, which

342 indicates that they are characterized by disparate vocalizations (Fig. S3). The analysis proposes

343 three discriminant functions (root) explaining 75.5\%, 16.9\% and 7.6\% of variance, respectively.

344 The first root distinctly separates A. agilis and the new Amazona from A. albifrons and A.

345 xantholora. The greatest contribution (expressed by standardized function coefficients) to the first

346 discriminant function has mean entropy (-1.210), syllable duration (-1.065), mean FM (0.969)

347 and mean of mean frequency (0.877). Syllable duration is most correlated (-0.686) with the first

348 root. The second discriminant function makes separate sets of syllables from A. agilis and the

349 new Amazona, whereas the sets of A. albifrons and A. xantholora overlap partially. The second

350 function is mostly associated with mean entropy (2.302) and mean of mean frequency (-2.227) as

351 well as correlated with mean amplitude (-0.313) and syllable duration (-0.308). The third root

352 separates $A$. albifrons and A. xantholora and is most related with variance of pitch goodness

353 (1.184), mean amplitude (1.094) and mean pitch goodness (-1.160). The largest correlations with

354 this function show mean $\mathrm{AM}^{2}(-0.502)$ and variance of $\mathrm{AM}(-0.501)$.

3.2. Molecular phylogenetic studies

356 Phylogenetic analyses were conducted on concatenated alignment of three genes: 12S rRNA, 16S

357 rRNA and COI. Both Bayesian and maximum likelihood analyses showed the same quite well-

358 resolved tree topology and relationships among the studied taxa (Fig. 12). Interestingly, none of

359 recognized biogeographic groups (Central and South America as well as the Greater and Lesser

360 Antilles) creates a strictly monophyletic clade that would include all members from the given

361 region.

362 The South America parrots are mixed with samples from the Lesser Antilles and Central America

363 (Fig. 12). The Lesser Antillean parrots are clearly separated into three independent lineages. $A$. 364 guildingii from the Lesser Antilles is significantly placed within the very distinctive group 365 including also the South American parrots, A. amazonica and A. brasiliensis. A sister lineage to 366 these species is A. imperialis from the Lesser Antilles. All four parrots form a group very well 367 supported by all methods. The third Lesser Antillean lineage contains A arausiaca and $A$. 368 versicolor. It also obtained very high posterior probability and bootstrap values but clearly 369 separates from the other Lesser Antillean parrots. The third lineage is very significantly related 
370 with Yellow-headed Amazon parrots from South America, namely A. aestiva, A. ochrocephala 371 and $A$. barbadensis.

372 The parrots from Central America are also split into three very well supported clades (Fig. 12). 373 The one including $A$. viridigenalis, A. finschi and A. autumnalis is placed within South America 374 parrots. The second clade including Yellow-headed Amazon parrots is closely affiliated to their 375 relatives from South America, namely A. aestiva and A. ochrocephala with a moderate support, 376 whereas the third clade is very significantly grouped with the Greater Antillean parrots, i.e. $A$. 377 agilis, A. collaria, A. vittata, A. leucocephala and $A$. ventralis.

378 This third clade contains parrots from Mexico and northern Central America, i.e., A. albifrons 379 albifrons, A. albifrons saltuensis, A. albifrons nana as well as the newly studied $A$. xantholora 380 and the newly described Amazona (Fig. 12). This clade branches off within the Greater Antillean 381 parrots making the latter paraphyletic. The sister taxon to the Central American parrots is $A$. 382 agilis from the Greater Antilles. The position of A. agilis received no support larger than 0.5 383 posterior probability and $50 \%$ bootstrap percentage but was indicated by all four applied 384 methods, two Bayesian and two maximum likelihood approaches. The other Greater Antillean 385 parrots form a clear monophyletic clade. To assess stability of phylogenetic position of A. agilis, 386 we carried out tree topology tests. They showed that trees in which A. agilis is clustered with 387 other Greater Antillean parrots (Fig. 13B) or placed at the base to all parrots from Central 388 America and the Greater Antilles (Fig. 13C) were not significantly worse that the best topology 389 (Fig. 13A).

390 The Mexican Amazona taxa are also monophyletic with A. xantholora placed at the base to the 391 clade with the largest possible support including three subspecies of $A$. albifrons and the new 392 Amazona. The taxa are split into two sister subclades that are well supported. One includes $A$. $a$. 393 albifrons and A. a. saltuensis, whereas the newly described Amazona taxon groups with $A$. 394 albifrons nana, with which it is sympatric. We also tested alternative topologies with different 395 placement of the new taxon (Fig. 13). Interestingly, the tree assuming earlier divergence of the 396 new taxon before differentiation of $A$. albifrons subspecies (Fig. 13D) was not significantly worse 397 than the best one (Fig. 13A). However, trees with clustering the new Amazona to A. xantholora 398 (Fig. 13E) or the basal placement of the new parrot to the rest Central America parrots (Fig. 13F) 399 were significantly worse. 
400 The branch leading to the new Amazona seems relatively short indicating a very small number of 401 substitutions in comparison to other lineages. The number of base differences per site (p-distance $402 \pm$ standard error) expressed as percent calculated for the three markers is $0.135 \pm 0.091$ between 403 the new Amazona and A. albifrons nana. However, it is about two times greater than the distance 404 between two subspecies, A. a. albifrons and A. a. saltuensis, which is $0.067 \pm 0.067$. Similar 405 conclusions can be drawn from distance calculation for individual markers but we decided to 406 present results for the concatenated sequences because of smaller stochastic error.

407 The performed molecular dating enabled to estimate divergence time of important events in the 408 evolution of Amazon parrots (Fig. 14). According to these estimations, the radiation of the 409 present lineages of Amazona started about 5 million years ago (mya). The South American 410 parrots begun their differentiation about 4.4 mya. The Lesser Antilles were settled from South 411 America independently three times about 3.2, 1.5 and 1.3-0.8 mya. The South American parrots 412 migrated also to Central America between 4.1 to 2.9 mya and also much later between 0.95 to 4130.55 mya giving two separate lineages. The radiation of the third Central America clade is dated 414 to 2.5 mya, whereas the whole group including additionally the Greater Antillean parrots started 415 its evolution about 3.5 mya. The small number of substitution indicates quite recent divergence of 416 the new Amazona from A. albifrons nana. Accordingly, molecular dating showed that their 417 lineages split by average 119 thousand years ago (kya) with 95\% credibility interval 9 - 270 kya 418 (Fig. 14). The two subspecies, A. albifrons albifrons and A. albifrons saltuensis diverged slightly 419 later about 89 kya.

\subsection{Diversification rate analyses}

421 To assess if and when Amazon parrots (including the newly described taxon) were subjected to 422 increase speciation rate, we performed diversification rate analyses. The calculated $\gamma$ statistic was $4231.509(\mathrm{p}$-value $=0.934)$ indicating no evidence for significant slowdown in the diversification. 424 Among eleven tested methods, a yule4rate appeared the best-fitted (Table S3). According to this 425 model, the first shift to a higher speciation rate (from 0.138 to 0.934 ) happened in $t_{1}=5.099$ mya 426 and lasted to $t_{2}=3.199$ mya, when the rate decreased to 0.229 . Since $t_{3}=1.305$ mya, the 427 speciation rate again have increased to 0.644 . The first increase is associated with radiation of the 428 basal Amazona lineages (Fig. 14). The period between $t_{1}$ and $t_{2}$ corresponds to the lowest 429 speciation of this genus. The final increase in diversification rate is related with emergence of 
430 closely related species and subspecies. Interestingly, this period corresponds to the more intensive 431 climate fluctuations in the Pleistocene started about 2 mya (Fig. 14A). In agreement with the 432 observation, we found significant positive correlation (Pearson correlation coefficient $=0.795$ 433 with $p$-value $=0.006$ ) between the rate of newly diverged lineages and the variance in the climate 434 fluctuations based on the $\delta^{18} \mathrm{O}$ curve from 2 mya to the present (Fig. 14B, C).

436 As a consequence of carried out analyses, we proposed the taxonomic position of the new 437 Amazona. The significant differences in morphometry, morphology, behavior and vocal features 438 imply that the new parrot deserves species status under the typological, morphological, phenetic, 439 as well as biological and evolutionary species concepts although genetic analyses suggest 440 differentiation at subspecies level.

\section{Amazona gomezgarzai, sp. nov. (Figs 2-7)}

442 Holotype. Adult male, MEXICO, the Yucatán Peninsula, south of Becanchén in Tekax 443 Municipality. The holotype is represented by the feathers of the male, which were deposited in 444 the collection of the Laboratorio de Ornitología, Facultad de Ciencias Biologícas, Universidad 445 Autonóma de Nuevo León, Mexico and were assigned catalog number: MGG01-Amazona 446 gomezgarzai-holotipo. Article 72.5.1 of the Code of Zoological Nomenclature (henceforth 447 CODE) permits the use of animal parts in the designation of a type specimen. Upon death of the 448 living bird, its preserved body will be paired to the feathers for a complete body. This complies 449 with Article 16.4.2 of the CODE, which states that where the holotype is an extant individual, a 450 statement of the intent to deposit the individual in a collection upon its death accompanied by a 451 statement indicating the name and location of that collection is sufficient.

452 Paratype. Adult female collected in the same locality as the holotype. Like the holotype, feathers 453 from this specimen have been deposited in the collection and have assigned catalog number: 454 MGG02-Amazona gomezgarzai-alotipo. Upon its death, it will be added to the collection in 455 Laboratorio de Ornitología, Facultad de Ciencias Biologícas, Universidad Autonóma de Nuevo 456 León, Mexico. 
457 Etymology. We take extreme pride in naming this parrot after Miguel Angel Gómez Garza, a 458 Mexican veterinarian born in Monterrey (Nuevo León, Mexico) in 1960. Gómez Garza's interest 459 in the ecology of the parrots of Mexico spans decades and culminated in the publication of a 460 work specifically dealing with the psittacines of that country (Gómez Garza 2014). During his 461 professional lifetime, Gómez Garza has been deeply involved in rehabilitating confiscated 462 wildlife. For the last thirty years, in his private veterinary clinic (Veterinaria del Valle) in 463 Monterrey, he has honorably supported the wildlife protection agency of the Republic of Mexico, 464 Procuraduría Federal de Protección al Ambiente (PROFEPA), providing medical attention to 465 confiscated wildlife suitable for being returned to their natural habitat. As a researcher in the 466 Facultad de Medicina Veterinaria y Zootecnia of the Universidad Autonóma de Nuevo León, he is 467 presently working on a veterinary protocol for confiscated psittacines intended for reintroduction 468 to the wild. He brought the existence of this unique member of the genus Amazona to our 469 attention and to him science and we owe a debt of gratitude. We suggest the common name in 470 English: Blue-winged Amazon and in Spanish: Loro de alas azules.

471 Diagnosis. The studied specimens show all of the characteristics of the genus as described by 472 Lesson (1831): "Rugged beak, very hooked, thick, banded edge or forming a flattened 473 depression, narrow, which follows the curvature of the beak, swollen sides, the scalloped edges; 474 the fringed lower mandible forward; nostrils rounded, very open in the wax and with protruding 475 flange; wings extending until one third of the tail; the tarses very short, reticulate, robust." Their 476 behavior, including display, is consistent with that of the genus and is closer to A. viridigenalis 477 than A. xantholora or A. albifrons, the birds being active and very vocal (pers. obs. senior author; 478 M.A. Gómez Garza, in litt., 2015).

479 A very distinctive feature of the new taxon is its call, which is loud, sharp, short, repetitive and 480 monotonous; one particular vocalization is more reminiscent of an Accipiter than of any parrot 481 we know (Supporting information Files S1 and S2). In flight, the call is a loud, short, sharp and 482 repetitive yak-yak-yak that is never repeated in pairs like in A. xantholora. While perched, the call 483 is mellow and prolonged, sharper and more melodious than that of Amazona albifrons. Perched 484 birds always respond to the call of another flock member, insuring that the parrots always 485 maintain contact with one another.

486 In general appearance, the new Amazona demonstrates a similarity to A. vittata of Puerto Rico 487 and to a lesser extent to A. tucumana from Bolivia and Argentina and Amazona pretrei from 488 Brazil and Argentina. A. vittata can be distinguished from the female of the new Amazona by the 
489 paler colored bill, larger and purer white orbital ring and more prominent grey bordering to the 490 feathers. Male of the new Amazona can be separated from A. vittata in addition by the presence 491 of rose-red feathers around the orbital ring.

492 A. pretrei exhibits dimorphism like the new Amazona but the male of A. pretrei displays 493 significantly redder feathering on the head and considerable red on the bend of the wing and 494 carpal edge; the red tone in $A$. pretrei is also richer. Indeed, both sexes of $A$. pretrei possesses 495 more extensive red feathering in the head, the color extending to forecrown and covering a 496 broader area around the orbital region; red feathers tend to appear scattered on the head; the bend 497 of wing and carpal area are covered in red as previously mentioned; the grey bordering to the 498 feathers is more prominent; and the bill is smaller, more proportionate and tends to have a 499 orangish hint, a color which intensifies with the breeding cycle.

500 The new Amazona is more phlegmatic in its behavior compared to the highly excitable and vocal 501 A. pretrei. In turn, A. tucumana differs by having a reddish triangle on the head, extending from 502 forehead to crown (a feature seen only in male of the new Amazona); there is an absence of 503 dimorphic head coloration; the grey bordering to the feathers is very prominent; the head is more 504 proportionate and the bill is whitish. In behavior, there are some affinities between $A$. tucumana 505 and the new Amazona.

506 Of the Mexican species, the new Amazona can easily be separated from A. xantholora by the 507 absence of yellow, white and blue from the head, from the green ear coverts and by the absence 508 of the prominent barring to the body feathers. The new taxon can be differentiated from $A$. 509 albifrons by the absence of white and blue from the head and by the green alula in both sexes, as 510 well as a larger size when compared to the sympatric A. albifrons nana.

511 The new Amazona resembles A. albifrons albifrons in size. Although its general color scheme is 512 closer to A. viridigenalis from northern Mexico (Table 2), the size difference is significant and 513 diagnostic as pointed out in Table 1 and 3. Moreover, the new Amazona has less red on the head 514 and possess neither the distinctive yellowish nape feathers that appear in elderly male $A$. 515 viridigenalis nor the red wing speculum found in A. viridigenalis.

\section{Description}

517 Male (holotype). Total length $26.6 \mathrm{~cm}$; wing (chord) $175.3 \mathrm{~mm}$; exposed culmen $27.8 \mathrm{~mm}$; tail $51889.6 \mathrm{~mm}$. The sex has been determined with molecular methods (Fig. S1). Upperparts, including 
519 nape, auriculars, dorsum, tertials, wing-coverts, rump and upper tail coverts parrot green, the 520 feathers of the head, nape, neck and mantle subtlety bordered black; forehead, forecrown and

521 feathers surrounding naked periophthalmic ring rose-red. Rear crown feathers subtlety bordered 522 in blue. Underside, chin, throat, breast and belly parrot green, the feathers from chin to vent 523 subtlety bordered in blue. Thigh feathers also washed in blue. Primaries (numbered descendently) 524 dark blue with flight feathers numbers 10 and 9 green on outer webs near base. Secondaries blue 525 with green margin on outer webs. Primary coverts blue, except along shaft, which is green. 526 Upperside of tail: two central feathers green; other feathers blue on outer web, red on inner web, 527 then yellowish green towards tip; all tail feathers are bordered in blue. Underside of tail: two 528 central feathers green, reddish hinted near feather shaft; other tail feathers rose-red on inner web, 529 yellowish at base and green towards tip; outer webs greyish-blue. Bill yellow, whitish at tip of 530 upper mandible. Tongue flesh grey, exposed nares naked and grey colored, periophthalmic ring 531 naked and greyish-white colored, iris pale mustard yellow, feet greyish-flesh colored and nails 532 grey, darkest at tip.

533 Female (paratype). Total length $24.7 \mathrm{~cm}$; wing (chord) $170.4 \mathrm{~mm}$; exposed culmen $25.7 \mathrm{~mm}$; tail $53483.7 \mathrm{~mm}$. The sex has been determined with molecular methods (Fig. S1). Like male but rose-red 535 confined to forehead.

\subsection{Additional characteristics}

537 Distribution. The new Amazona is endemic to the Yucatán Peninsula in southern Mexico. To date, 538 its presence is confined to an area roughly $100 \mathrm{~km}^{2}$ that is centered south of Becanchén in Tekax 539 Municipality, Yucatán. No part of the range is presently protected in any form.

540 Habitat. The new Amazona is found in tropical caducifolius and subcaducifolius forest. It is also 541 found in disturbed patches of native vegetation and in small, cultivated fields with scattered trees. 542 It is found below $300 \mathrm{~m}$ above sea level.

543 Natural history. Miguel A. Gómez Garza first sighted this parrot in the field in trees of the 544 Leucaena genus at heights of approximately 6 meters in the beginning of 2014 during a visit to 545 the south of Becanchén, in the municipality of Tekax. The parrots occurred in small flocks of 546 three to five individuals and fed on the tender pods produced by this tree. During a follow up visit 547 in August 2014, Gómez Garza also sighted pairs with their fledged young. This field work 
548 confirmed the rarity of the species and that it was far less common than the other two species

549 found in the same area, Amazona albifrons nana and Amazona xantholora.

550 In normal parrot fashion, the new Amazona is diurnal, beginning the day at sunrise. It is generally 551 secretive when resting, using its plumage as camouflage. In contrast, it is vocal and noisy in 552 flight. The flight is moderately fast with the mechanism that is typical of the genus Amazona with 553 wing-beats never exceeding the horizontal axis.

554 The new Amazona is found in small flocks of less than 12 individuals, which were studied in the 555 field. Pairs and their progeny have a tendency to remain together and are discernible in groups. 556 Like all members of the genus Amazona, this parrot is herbivore. Its diet consists of seeds, fruits, 557 flowers and leaves obtained in the tree canopy. It also consumes tender shoots of native trees and 558 the pods of leguminous trees including uaxim (Leucaena glauca), bukut (Cassia grandis) and 559 katsín (Acasia gaumeri).

560 Very little is known about this parrot's biology. There is no conservation program currently in 561 effect to preserve this parrot but its long-term existence impinges on the local communities and 562 making them aware of this parrot's value as a result of its uniqueness, its potential as a bird 563 watching attraction and the fact that it is present only locally. Its small range and rarity should 564 make its conservation a priority.

566 4.1. Taxonomic position of the newly described Amazona

567 In this study, we proposed the new taxon of Amazona at the species level, Amazona gomezgarzai $568 \mathrm{sp}$. nov. The species level is supported by morphometrical and behavioral data, whereas 569 mitochondrial genetic analyses imply the subspecies level. Below we discussed the pros and cons 570 of these two taxonomic concepts in an objective way.

571 Multivariate analysis incorporating both metric and morphological features clearly separated the 572 new Amazona from the other Mexican parrots, which in turn differed distinctly from $A$. 573 autumnalis and $A$. viridigenalis (Fig. 8-10). The newly described taxon showed the closest 574 morphometric similarity to A. xantholora. However, it clearly separates in vocalization features 575 from two other Central American parrots (A. albifrons and A. xantholora) and their Greater 576 Antillean relative A. agilis (Fig. 11 and Fig. S3). 
577 Based on the phylogenetic analysis performed, this new taxon is undoubtedly grouped within the

578 clade of Mexican congeners, namely Amazona albifrons albifrons, A. a. nana, A. a. saltuensis and 579 A. xantholora (Fig. 14). Although the new Amazona shows some morphological similarity to $A$. 580 vittata, these two taxa are clearly separated into two clades in the phylogeny. The closest relative 581 of the new Amazona is A. a. nana, also from the Yucatán Peninsula. The other two subspecies of 582 Amazona albifrons (A. a. albifrons and A. a. saltuensis) included in the same clade are distributed 583 along the Pacific slope of Mexico (Gómez Garza 2014) and surely share the same ancestors as 584 the forms from the Yucatán Peninsula. The common origin of these taxa, along with the newly 585 described form, is concordant in several common features, such as sexual dimorphism and similar 586 plumage coloration with the presence of red on the head (Fig. 3).

587 Nonetheless, the new Amazona is clearly different from A. albifrons. Although the three Mexican 588 parrots found in the Yucatán Peninsula (A. albifrons nana, A. xantholora and the new Amazona) 589 share the same habitat and come into frequent physical contact, they live commensally and show 590 substantial differences in their morphology, plumage, call and behavior (Table 1-3, Fig. 3, 11, 591 S3). The features used here to discriminate the proposed taxon are of the same type as those 592 utilized in elevation of other Amazona species. The characters described allow the species to live 593 sympatrically without hybridizing (Pettingill 1970). This suggests that these three forms are 594 separate species. The differentiation in characters involved in mate choice, such as song, 595 plumage, and behavior play a central role in avian speciation (Edwards et al. 2005). The role of 596 song is particularly interesting because multiple factors influence vocal evolution and this feature 597 is subjected to rapid change through learning and behavioral evolution.

598 Studies of geographic variation in the vocalizations of the crimson rosella (Platycercus elegans) 599 parrot species complex showed that vocal variation, in a species with vocal learning, can coincide 600 with areas of restricted gene flow across geographically continuous populations. These results 601 suggest that vocalization can be associated with reduced gene flow between populations, and 602 therefore may promote speciation, even in the absence of other barriers (Ribot et al. 2012). On 603 the other hand, several local dialects were documented for Amazona auropalliata with no 604 significant relationship with genetic variations (Wright \& Wilkinson 2001) indicating a high 605 degree of gene flow and individual dispersal across the dialect boundaries. Experimentally 606 simulated dispersals with Amazona auropalliata individuals moving within and across dialect 607 regions showed that both vocal learning (in the case of juveniles) and limited dispersal (in the 608 case of adults) are responsible for the dialect maintenance (Salinas-Melgoza \& Wright 2012). 
609 Although recent studies on contact calls of Neotropical parrots from the tribe Arini (related to 610 Androglossini) showed evolutionary rates similar (but not accelerated) to those of morphological 611 traits, the calls contained significant levels of phylogenetic signal and evolution of some acoustic 612 parameters correlated with evolution of body mass and bill length (Medina-Garcia et al. 2015). 613 The coordinated evolution of these features can facilitate speciation of parrots.

614 On the other hand, it could be possible that the studied individuals of the new taxon are hybrids 615 or aberrant forms of Amazona albifrons and the observed morphometric differences result from 616 intraspecific variation in A. albifrons. However, the length of wings and tail of the newly 617 described parrots are out of the range of these characters in all three Amazona albifrons 618 subspecies. The red forehead, green crown and distinct black scalloping contour feathers were not 619 observed in A. albifrons too. Field studies carried out by Miguel A. Gomez Garza and others 620 during the past 30 years have revealed no individuals of $A$. albifrons showing such mixed 621 characters. Similarly, local informants and the staff at PROFEPA (Procuraduría Federal de 622 Protección al Ambiente) and CIVIS (Center for the Conservation and Research of Wildlife), 623 which is managed by the government in the same municipality of Tekax, have never seen such 624 potential hybrids or $A$. albifrons with the atypical features among the hundreds of all parrots 625 confiscated in the range area each year, either. Such forms were not observed also among the 626 hundreds of all parrot specimens imported through the US quarantine system from 1973 to 2008 , 627 when a ban was introduced on export of parrots.

628 The Kawall's Amazon (Amazona kawalli) was also initially considered an aberrant form of Mealy 629 Parrot (Amazona farinosa) before it was recognized as the new species (Martuscelli \& Yamashita 630 1997). Nevertheless, more extensive studies including larger number of $A$. albifrons specimens 631 are necessary to verify its variation because aberrant forms are not unusual in parrots.

632 The distinct morphological and behavioral features seem incongruent with molecular 633 phylogenetic results, in which the new Amazona and A. albifrons nana are clustered together 634 leaving outside the two A. albifrons subspecies. It would suggest that the new taxon should be a 635 subspecies within A. albifrons. However, the alternative placement of the new Amazona at the 636 base to the monophyletic $A$. albifrons clade is not significantly worse than the best tree (Fig. 637 13D). It suggests that the new taxon could have emerged before differentiation of $A$. albifrons to 638 subspecies and has reached a species level. Interestingly, such alternative topology was obtained 639 for hierarchical clustering of parrots based on all morphometric characters (Fig. 10). Moreover, 640 the molecular distance between the new Amazona and A. albifrons nana measured by the number 
641 of base differences per site $(0.135)$ is even about two times greater than the distance $(0.067)$

642 between two A. albifrons subspecies, A. a. albifrons and A. a. saltuensis.

643 The acceptance of the new Amazona as a species would imply that the $A$. albifrons taxon would 644 be paraphyletic. In consequence, A. albifrons nana could be also admitted a species status. 645 However, it is not sufficiently different in morphology and morphometry from other subspecies 646 of $A$. albifrons to be elevated to the new species. It should be noted that the paraphyly of 647 Amazona taxa is not an exceptional case because the same situation concerns Central American 648 A. oratrix and A. auropalliata, whose sequences are mixed and do not form one-species 649 monophyletic clades (Fig. 12). Similarly, A. ochrocephala is also paraphyletic whose 650 representatives group with $A$. aestiva, A. barbadensis and the clade A. oratrix - A. auropalliata. It 651 cannot be excluded that some specimens (e.g. A. ochrocephala) were misidentified and the 652 taxonomy of the genus Amazona should be substantially revised.

653 The resulted paraphyly of A. albifrons caused by the new Amazona does not have to be an 654 extraordinary case, either. The comprehensive surveys and meta-analyses of mitochondrial gene 655 phylogenies pointed out that such paraphyletic or polyphyletic species constitute a substantial 656 fraction (19-23\%) of thousands animal taxa studied, including four parrot species from the 657 Cacatuidae family (Funk \& Omland 2003; Ross 2014). The major natural reasons of species658 level paraphyly and polyphyly can be introgression and incomplete lineage sorting following 659 recent speciation. However, following Haldane's rule (Haldane 1922), the introgression of 660 maternally inherited mtDNA is restricted between heterogametic avian species because female 661 hybrids are characterized by a reduced viability (Brumfield et al. 2001; Carling \& Brumfield 662 2008; Rheindt \& Edwards 2011; Saetre et al. 2001; Saetre et al. 2003; Tegelstrom \& Gelter 1990; 663 Turelli \& Orr 1995). Mitochondrial genes are also less prone to the incomplete sorting than 664 nuclear loci because they are present in a haploid genome and maternally inherited (Hudson \& 665 Turelli 2003). However, this effect can influence mtDNA in rapidly radiating taxa, in which on666 going speciation occurs before genetic sorting (Funk \& Omland 2003).

667 Assuming that the current phylogeny reflects real relationships between Amazon parrots, we can 668 accept that the paraphyletic species, including the new Amazona, have emerged quite recently 669 within other species from their isolated subspecies. In the case of the new Amazona, its lineage 670 diverged most probably about 120,000 years ago within A. albifrons (Fig. 14). During this time, 671 the taxon differentiated sufficiently to be clearly recognizable by many morphometric and 672 behavioral features. In agreement with that, the genetic distance between the new Amazona and 
673 A. a. nana is two times larger than that between their closest relatives A. a. albifrons and $A$. $a$. 674 saltuensis.

675 The taxon described here, morphologically and behaviorally different from other members of the 676 genus found in Mexico, is not an exception regarding the small genetic distance. There are many 677 examples of birds with minor genetic differences that are treated as valid species, e.g. Apus 678 apus/A. pallidus (Päckert et al. 2012), Clanga clanga/C. pomarina (Helbig et al. 2005; Lerner et 679 al. 2017) and Falco rusticolus/F. biarmicus/F. cherrug (Nittinger et al. 2007). Recent estimates of 680 avian diversity suggest that the current taxonomy of birds underestimates their species number by 681 at least a factor of two (Barrowclough et al. 2016). Subsequent studies of the new Amazona 682 should be carried out to deliver additional information about this interesting parrot.

684 Our results have also interesting implications for phylogeography of the whole genus Amazona 685 and colonization of Central America as well as Lesser and Greater Antilles. The obtained results 686 indicate that Central America was settled three times independently at different times from 687 distinct ancestral lineages. Two times their ancestors were South American parrots and the 688 immigrations happened 4-3 mya and 1-0.5 mya. It is in good agreement with the standard 689 assumption on the formation of the Panama Isthmus, whose final closure is proposed to have 690 occurred just 4-3 mya (see (Montes et al. 2015) for the much earlier dating, which also supports 691 our estimations). The third case is more controversial because the clade does not cluster directly 692 with any South American parrots but with those from Greater Antilles. The observed proximity of 693 the Mexican Amazona albifrons clade with the Greater Antillean clade composed of Amazona 694 collaria, A. vittata, A. leucocephala, A. ventralis and A. agilis suggests the continental origin of 695 the island parrots (Bond 1963; Lack 1976; Lantermann 1997; Ottens-Wainright et al. 2004; 696 Russello \& Amato 2004; Snyder et al. 1987; Wiley 1991). Two colonization events of the Greater 697 Antilles from Central America, i.e. Yucatan Peninsula and Honduran-Nicaraguan Bulge were 698 proposed (Bond 1963; Lack 1976; Lantermann 1997; Snyder et al. 1987; Wiley 1991). It was 699 hypothesized that one invasion could have occurred through Jamaica (by lineage of A. agilis) and 700 the second through Cuba (by A. leucocephala from which other Jamaica parrot $A$. collaria would 701 derive) (Lack 1976; Lantermann 1997; Snyder et al. 1987; Wiley 1991). Ottens-Wainright et al. 702 (2004) proposed also two colonization events but both directed to Jamaica. 
703 Our phylogenies including the largest number of Amazona representatives from Central America

704 do not split the Greater Antillean parrot clade into two groups as it would be expected in the case

705 of the two-colonization scenario. Just the opposite, they show that the Central America clade is 706 nested within the Greater Antillean parrot group. Such branching order results from the basal 707 position of the quite diverged lineage of $A$. agilis to the Central American parrots. In the LogDet 708 model-based tree by Ottens-Wainright et al. (2004), the consensus of 12 equally most 709 parsimonious trees by Russello \& Amato (2004), and Bayesian Beast tree by Schweizer et al. 710 (2014), the Central America clade was also placed within the Greater Antillean parrot group but 711 in these cases $A$. agilis was basal to both Central America and Greater Antilles clades. These two 712 alternative topologies are not statistically different but the first one is favored (Fig. 13A, C). The 713 topology assuming the separation and monophyly of the Central American and the Greater 714 Antillean parrots was not rejected by the applied tests, either (Fig. 13B). However, taken into 715 account that the first topology (Fig. 13A) was inferred by all four applied methods and the 716 Greater Antillean parrot clade, including A. agilis, shows a greater genetic variation and older 717 divergence time than the Central America clade, it is possible that a migration happened from the 718 Greater Antilles to Mexican territory. In this scenario, the Greater Antillean parrots would be 719 derived from species inhabiting northern South America, whose lineages became extinct and 720 therefore are not present in inferring phylogenies. According to our molecular dating, the 721 colonization of the Central America could happen between 3.4 to 2.5 mya (Fig. 14). These event 722 is in agreement with dating of decrease in sea level, which started to systematically fall since 3 723 mya and in the period 3.4 to 2.5 mya descended even $50 \mathrm{~m}$ below the present level (Hansen et al. 724 2013), which could have facilitated the migrations.

725 In the case of the Lesser Antillean parrots the situation seems clearer. The presence of three 726 separated clades placed within South American parrots suggests independent migrations from the 727 mainland to the islands as proposed by Bond (1963). Our estimations indicate that it could have 728 happened about 3.2, 1.5 and 1.3-0.8 mya, which well correspond with the decrease in sea level 729 initially by $25 \mathrm{~m}$ and after 2.5 mya by more than $50 \mathrm{~m}$ with relation to the Pleistocene glaciations 730 (Hansen et al. 2013). However, we cannot exclude the opposite direction of migrations, from 731 islands (the Lesser Antilles) to the mainland (the northern coast of Venezuela) as it was recently 732 proposed for the origin of Yellow-headed Amazon parrots (Urantowka et al. 2014). Nevertheless, 733 the obtained results show a complex history for parrots within the Caribbean region (Russello \& 
734 Amato 2004) related probably with the refugial and insular character of its habitats. Additional

735 studies are required to solve in detail the migration routes.

736 The Amazon parrots have been subjected to evolutionary expansion since the last 5 mya. Their 737 earliest diversification may be associated with adaptive radiation which has been triggered by the 738 arrival of Arini parrots in South America from Africa (Schweizer et al. 2014). Other important 739 factors could be drainage evolution in Amazonia and Pleistocene climatic oscillations (Fig. 14) 740 causing alterations and partitioning of habitats, sea level changes influencing colonization of 741 islands (and again mainland) as well as recurrent elevational migrations (Ribas et al. 2012; Rull 742 2011; Schweizer et al. 2014). These processes could cause the differentiation of populations into 743 new lineages. One of such recently evolving lineage could represent the newly described Amazon 744 parrot. Schweizer et al. (2014) studying the diversity of Neotropical parrots (including members 745 of Arini and Androglossini clades) found no evidence of the slowdown in their speciation rate and 746 discovered two young, unexpectedly species-rich clades represented by Pyrrhura and Aratinga. 747 Although these two clades originated in the late Miocene/Pliocene, speciation within each clade 748 took place mainly during the Pleistocene. The same can be observed in the case of at least some 749 Amazona lineages (Fig. 14).

\section{Conservation aspects}

751 If the newly described Amazona represents the species status must be regarded as critically 752 endangered (CR) based on IUCN (International Union for the Conservation of Nature) Red List 753 of Species criteria, as all new species described in recent decades. Its habitat has been 754 significantly altered. This parrot is confined to a small area and no parts of its range are currently 755 protected. Because of this precarious status, the Mexican wildlife authorities are urged to regard 756 it as "Especie en Peligro de Extinción" (Endangered species), in following established guidelines 757 (Norma Oficial Mexicana NOM-059-SEMARNAT-2010). This Amazona does not undergo 758 displacement, making them confined to a small area of lowland native forest and interspersed 759 altered plots containing native vegetation. Through the publication of this description, we are 760 alerting government authorities, conservationists and local inhabitants that implementing 761 conservation measures is imperative to provide refuge for a broad array of species found within 762 the range of Amazona (albiforns) gomezgarzai, including this unique new member of the genus 763 Amazona. Because of this precarious status, the Mexican government would not allow the 
764 collection of voucher specimens. Instead the authorities permitted that two individuals 765 maintained locally as pets be transported for safe keeping under the care of Dr Miguel Angel 766 Gómez Garza.

\section{6. Acknowledgements}

768 We would like to thank the Mexican authorities at Procuraduría Federal de Protección al 769 Ambiente (PROFEPA) but in particular the former head of Natural Resources, Alejandro del 770 Mazo Maza, as well as Ana Romo, Joel González and Saúl Colín for their cooperation in 771 procuring specimens. Molecular sexing and mtDNA sequence studies were carried out by 772 Ricardo Canales of the Laboratorio de Biología de la Conservación y Desarrollo Sustentable, 773 Facultad de Ciencies Biologicas, Universidad Autonóma de Nuevo León and to him we are most 774 grateful. We also express our appreciation to José I. González Rojas, chief of the department of 775 ornithology of the same institution, who provided access for the study and measurement of 776 comparative material. Aldegundo Garza de León of the Museo de las Aves de México in Saltillo, 777 gave us unfettered access to the collection. Juan García Venegas did the illustrations. Miguel A. 778 Pérez Hassaf, Eduardo Serio, Ricardo Cantú López, Edgar Villarreal, Daniel Garza Tobón, Carlos 779 Leal, Jorge Verduzco, and Roberto Chavarría provided comments and suggestions to improve this 780 paper. Finally, the late Ramon Noegel and Helmut Sick instilled a passion for these parrots that to 781 this day pervades in our soul. We are very grateful to Norbert Bahr and other Reviewers for their 782 valuable comments and insightful remarks that significantly improved the paper. 
783 Table 1. Morphometric data (in millimeters) of the new Amazona compared with other similarly 784 red-fronted and-faced species of Amazona.

\begin{tabular}{|c|c|c|c|c|c|c|c|}
\hline Feature & $\begin{array}{c}\text { New } \\
\text { Amazona }\end{array}$ & A. a. nana & A.a. albifrons & A. a. saltuensis & A. xantholora & A. autumnalis & A. viridigenalis \\
\hline Wing & $\begin{array}{l}175.3 \hat{\circ} \\
170.4 \text { + }\end{array}$ & $\begin{array}{c}167.3 \bigcirc \\
\text { (Range 149.9- } \\
170.3 \text { ) } \\
152.99 \\
\text { (Range 133.8- } \\
162.53 \text { ) }\end{array}$ & $\begin{array}{c}180.9 \AA \\
\text { (Range 179.3- } \\
191.0 \text { ) } \\
174.2 \text { } \\
\text { (Range 170.7- } \\
177.9 \text { ) }\end{array}$ & $\begin{array}{c}182.8 \hat{0} \\
\text { (Range 175.4- } \\
191.3 \text { ) } \\
180.0 \text { 9 } \\
\text { (Range 177.4- } \\
184.2 \text { ) }\end{array}$ & $\begin{array}{c}165.10 \\
\text { (Range 153.0- } \\
170.8 \text { ) } \\
169.3 \text { 促 } \\
\text { (Range 166.8- } \\
170.3 \text { ) }\end{array}$ & $\begin{array}{c}217.8 * \\
\text { (Range 212.7- } \\
\text { 223.0) }\end{array}$ & $\begin{array}{c}202.4 \hat{0} \\
\text { (Range 197.1- } \\
209.1 \text { ) } \\
197.8 \text { + } \\
\text { (Range 189.9- } \\
\text { 201.3) }\end{array}$ \\
\hline Tail & $\begin{array}{l}89.6 \text { ○ } \\
83.7 \text { क }\end{array}$ & $\begin{array}{c}73.8 \hat{\circ} \\
\text { (Range } 71.9-80.1) \\
76.5 \text { o } \\
\text { (Range } 74.6-80.1 \text { ) }\end{array}$ & $\begin{array}{c}76.10 \\
\text { (Range } 73.5- \\
83.2 \text { ) } \\
77.99 \\
\text { (Range 75.7- } \\
81.9 \text { ) }\end{array}$ & $\begin{array}{c}76.8 \text { o } \\
\text { (Range } 72.9- \\
83.1) \\
78.89 \\
\text { (Range 76.1- } \\
80.8)\end{array}$ & $\begin{array}{c}77.20 \\
\text { (Range } 74.8- \\
79.9 \text { ) } \\
77.49 \\
\text { (Range } 75.3- \\
79.3 \text { ) }\end{array}$ & $\begin{array}{c}100.8 * \\
\text { (Range } 95.1- \\
106.5 \text { ) }\end{array}$ & $\begin{array}{c}104.6 \hat{0} \\
\text { (Range 89.2- } \\
117.1 \text { ) } \\
105.3 \% \\
\text { (Range 103.5- } \\
107.4 \text { ) }\end{array}$ \\
\hline $\begin{array}{l}\text { Exposed } \\
\text { culmen }\end{array}$ & $\begin{array}{l}27.8 \text { ๙ } \\
25.7 \stackrel{+}{+}\end{array}$ & $\begin{array}{c}26.4 \hat{\circ} \\
\text { (Range } 24.9-30.5) \\
24.9 \text { ) } \\
\text { (Range } 24.7-25.2)\end{array}$ & $\begin{array}{c}26.5 \hat{0} \\
\text { (Range 24.0- } \\
28.1 \text { ) } \\
24.2 \text { \% } \\
\text { (Range 23.6- } \\
25.2 \text { ) }\end{array}$ & $\begin{array}{c}25.10 \\
\text { (Range 23.8- } \\
27.3 \text { ) } \\
24.0 \text { 9 } \\
\text { (Range 23.8- } \\
27.5 \text { ) }\end{array}$ & $\begin{array}{c}26.10 \\
\text { (Range 25.4- } \\
26.6 \text { ) } \\
24.8 \text { + } \\
\text { (Range 24.7- } \\
25.0 \text { ) }\end{array}$ & $\begin{array}{c}30.4 * \\
\text { (Range 27.9- } \\
32.9)\end{array}$ & $\begin{array}{c}29.9 \AA \\
\text { (Range 28.5- } \\
31.7 \text { ) } \\
27.0 \text { q } \\
\text { (Range 24.2- } \\
28.6)\end{array}$ \\
\hline
\end{tabular}

785 Three individuals of each sex were measured for each taxon, except for Amazona autumnalis in which six 786 birds of unknown sex were taken into account. Data were collected from living birds of known 787 provenance and preserved skins in the collection of the Museo de las Aves de México (MAM), in Saltillo. 788 The museum specimens are identified as: Amazona albifrons albifrons MAM 1076; A. albifrons nana 789 MAM 2780, MAM 2217, MAM 2988, MAM 2433, MAM 1726; A. viridigenalis MAM 132, MAM 133, 790 MAM 2725, MAM 1878, MAM 1548, MAM 1715, MAM 1723, MAM 1775, MAM 1377, MAM 2216, 791 MAM 1547; A. autumnalis autumnalis MAM 2989, MAM 2987, MAM 1883, MAM 2448, MAM 1827, 792 MAM 134; A. xantholora MAM 1948, MAM 737; * Unsexed specimens. Geographic origin of studied 793 individuals: A. albifrons nana: Zoologico de Merida, from the local population; Amazona albifrons 794 albifrons: Planetaro Alfa, Monterrey, from the Guerrero population; Amazona albifrons saltuensis: 795 Acuario de Mazatlán (a public aquarium that also displays birds), from Sinaloa specimens; A. xantholora: 796 Zoologico de Merida, from the local population; A. autumnalis autumnalis: Planetario Alfa, from the 797 southern Tamaulipas population; A. viridigenalis: Planetario Alfa, from the southern Tamaulipas 798 population. 
799 Table 2. Comparison of differences in face coloration of the new Amazona and other similarly 800 red-fronted and-faced species of Amazona from Mexico and Mesoamerica.

\begin{tabular}{|l|l|l|l|l|l|c|}
\hline \multicolumn{1}{|c|}{ Species } & Forehead & Lores & Cheeks & Crown & $\begin{array}{c}\text { Black } \\
\text { ear } \\
\text { patch }\end{array}$ & $\begin{array}{c}\text { Black } \\
\text { scalloping } \\
\text { contour } \\
\text { feathers } \\
\text { (face) }\end{array}$ \\
\hline New Amazona & red & red & green & green & absent & present \\
\hline A. albifrons nana & white & red & green & bluish & absent & subtle \\
\hline A. a. albifrons & white & red & green & blue & absent & subtle \\
\hline A. a. saltuensis & white & red & green & blue & absent & subtle \\
\hline A. xantholora & white & yellow & green & bluish & present & present \\
\hline $\begin{array}{l}\text { A. autumnalis } \\
\text { autumnalis }\end{array}$ & red & red & yellow & bluish & absent & absent \\
\hline A. viridigenalis & red & red & green & bluish & absent & absent \\
\hline
\end{tabular}


801 Table 3. Morphological traits of the new Amazona compared with other similarly red-fronted and

802 -faced species of Amazona, including other species occurring in the Yucatán Peninsula ( $A$.

803 albifrons nana, A. xantholora, A. autumnalis).

\begin{tabular}{|c|c|c|c|c|c|}
\hline Species & $\begin{array}{l}\text { Average } \\
\text { weight } \\
\text { (grams) }\end{array}$ & $\begin{array}{l}\text { Average } \\
\text { length } \\
\text { (cm) }\end{array}$ & Head coloration & Wing coloration & Tail coloration \\
\hline New Amazona & 200 & 25 & $\begin{array}{l}\text { Male: Forehead and forecrown } \\
\text { red; rear crown feathers subtle } \\
\text { bluish tipped; periophthalmic ring } \\
\text { red. } \\
\text { Female: Forehead red. }\end{array}$ & $\begin{array}{l}\text { Underside of wings green, } \\
\text { except tips of primaries which } \\
\text { are bluish green. }\end{array}$ & $\begin{array}{l}\text { Green, bluish tipped; } \\
\text { three lateral tail feathers } \\
\text { red on inner part. }\end{array}$ \\
\hline $\begin{array}{l}\text { A. albifrons } \\
\text { nana }\end{array}$ & $\begin{array}{l}205 \text { (range } \\
198.1- \\
213.0)\end{array}$ & 23 & $\begin{array}{l}\text { Male: forehead and forecrown } \\
\text { white, posterior border blue; } \\
\text { periophthalmic ring and lores red. } \\
\text { Female: white on forehead and } \\
\text { red of periophthalmic ring greatly } \\
\text { reduced. }\end{array}$ & $\begin{array}{l}\text { Primary coverts red in male, } \\
\text { green or red greatly reduced in } \\
\text { most females; primaries green, } \\
\text { dark blue towards tip; } \\
\text { secondaries blue; under-wing } \\
\text { coverts green. }\end{array}$ & $\begin{array}{l}\text { Green, yellowish-green } \\
\text { towards tip; base of } \\
\text { lateral feathers red. }\end{array}$ \\
\hline A. a. albifrons & $\begin{array}{l}230 \text { (range } \\
207.4- \\
244.4 \text { ) } \\
\end{array}$ & 26 & $\begin{array}{l}\text { As } A . \text { a. nana, but green slightly } \\
\text { darker. }\end{array}$ & As $A$. a. nana. & As $A$. a. nana. \\
\hline A. a. saltuensis & $\begin{array}{l}230 \text { (range } \\
211.9- \\
233.5 \text { ) } \\
\end{array}$ & 26 & $\begin{array}{l}\text { As } A \text {. a. albifrons, but blue crown } \\
\text { extends to nape. }\end{array}$ & As $A$. a. nana. & As $A$. a. nana. \\
\hline A. xantholora & $\begin{array}{l}200 \text { (range } \\
197.1- \\
238.2 \text { ) }\end{array}$ & 23 & $\begin{array}{l}\text { Male: Forehead and forecrown } \\
\text { white, posterior blue; lores } \\
\text { yellow; periophthalmic ring red; } \\
\text { ear coverts preeminently black. } \\
\text { Female: all head colors } \\
\text { significantly reduced, except for } \\
\text { the crown, which is blue. }\end{array}$ & $\begin{array}{l}\text { Primary and secondary flight } \\
\text { feathers green, blue towards } \\
\text { tip; underside of wings } \\
\text { greenish-blue; red on shoulder } \\
\text { present in some individuals, } \\
\text { mainly males. }\end{array}$ & $\begin{array}{l}\text { Tail green, yellowish- } \\
\text { green towards edge; } \\
\text { lateral tail feathers red at } \\
\text { base. }\end{array}$ \\
\hline $\begin{array}{l}\text { A. autumnalis } \\
\text { autumnalis }\end{array}$ & $\begin{array}{l}350 \text { (range } \\
338.9- \\
369.0)\end{array}$ & 34 & $\begin{array}{l}\text { Forehead and upper part of lores } \\
\text { red, lower part of lores and } \\
\text { cheeks yellow, strongly hinted } \\
\text { with red in some individuals from } \\
\text { Mexico; crown blue }\end{array}$ & $\begin{array}{l}\text { Primary and secondary flight } \\
\text { feathers green, becoming dark } \\
\text { blue towards tips; first five } \\
\text { secondaries with red wing- } \\
\text { speculum. }\end{array}$ & $\begin{array}{l}\text { Green with greenish- } \\
\text { yellow tips; outer webs } \\
\text { of outer tail feathers } \\
\text { blue. }\end{array}$ \\
\hline A. viridigenalis & $\begin{array}{l}270 \text { (range } \\
266.4- \\
299.2 \text { ) }\end{array}$ & 33 & $\begin{array}{l}\text { Forehead, upper lores and crown } \\
\text { red; dark blue extends from rear } \\
\text { part of eye and occiput to encircle } \\
\text { cheeks, which are lighter green. } \\
\text { Females have less red on head } \\
\text { and some old males acquire } \\
\text { several yellow feathers to the } \\
\text { nape. }\end{array}$ & $\begin{array}{l}\text { Outer webs of primaries violet- } \\
\text { blue; secondaries with blue } \\
\text { tips; first five secondaries with } \\
\text { red wing-speculum. }\end{array}$ & $\begin{array}{l}\text { Green, with green- } \\
\text { yellow tips. }\end{array}$ \\
\hline
\end{tabular}

804 Three individuals of each sex were measured for each taxon, except for Amazona autumnalis, in which six

805 birds of unknown sex were taken into account. 


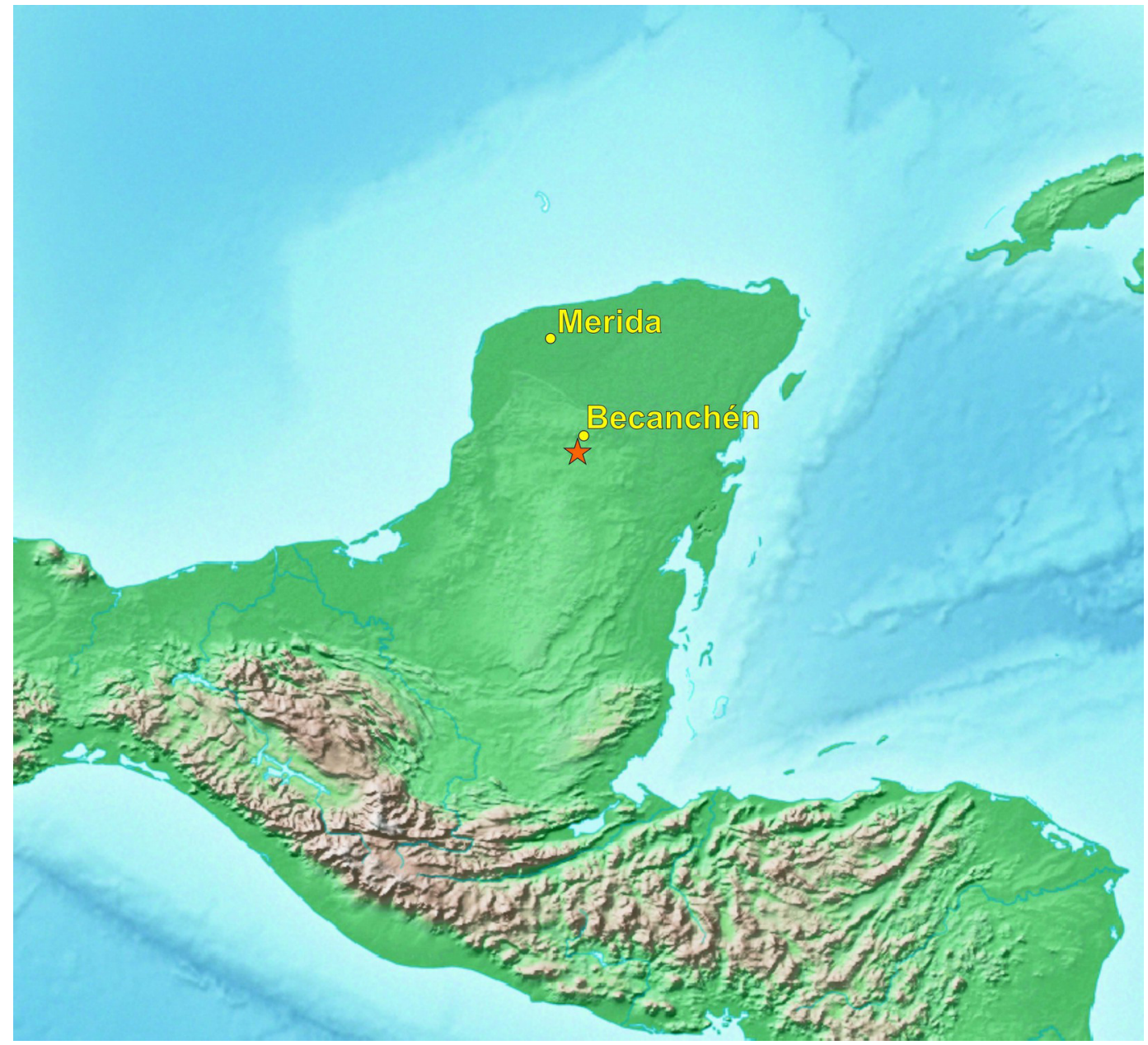

806 Fig. 1. Map of Yucatán Peninsula with the location of site (asterisk), where the new Amazona was 807 found. 


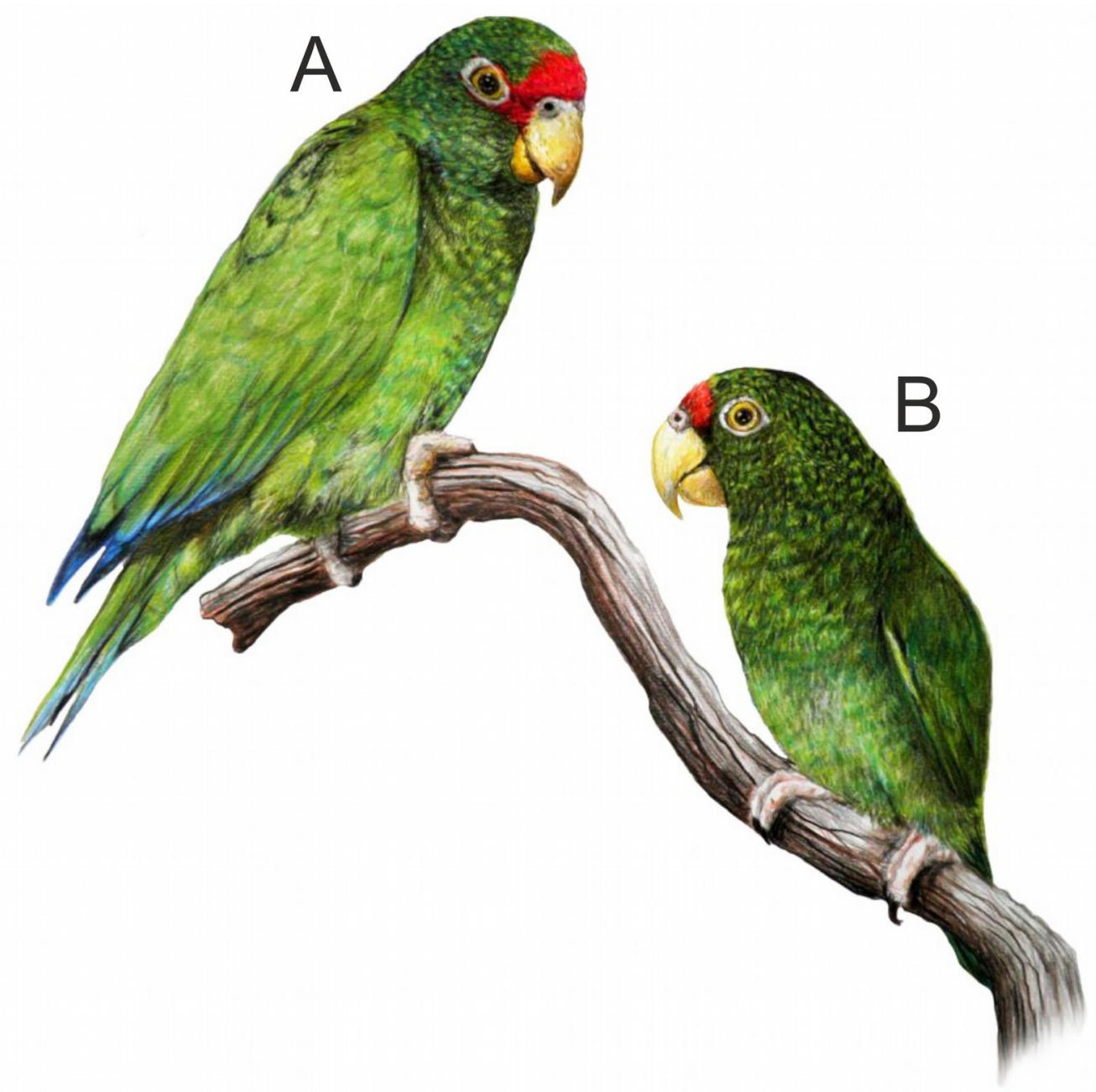

808 Fig. 2. Illustration of the new Amazona. Male holotype (A) and female paratype (B). 

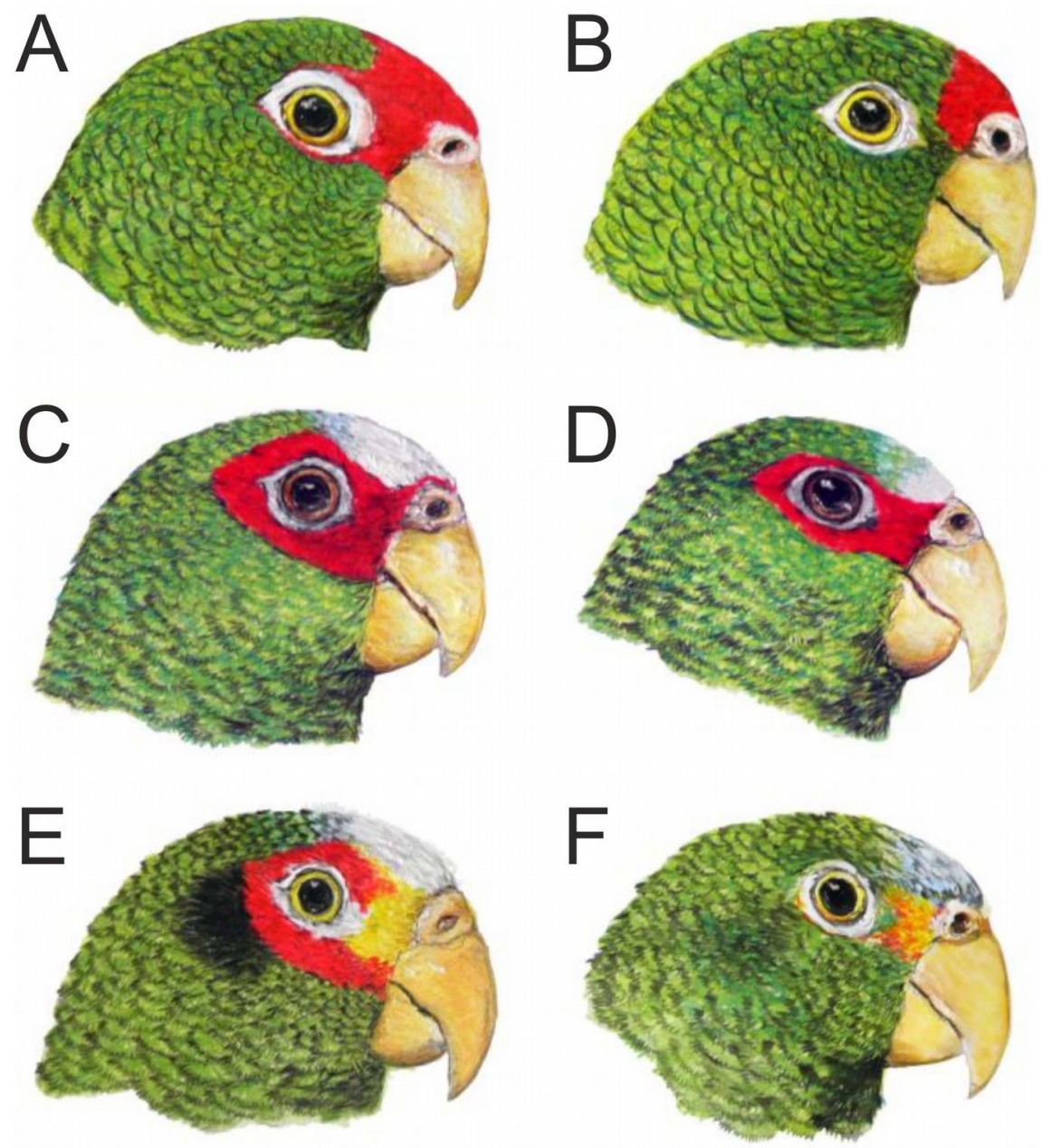

809 Fig. 3. Head coloration in the male (A) and female (B) of the new Amazona in comparison to

810 both sexes of congeners Amazona albifrons nana (C - male; D - female) and Amazona 811 xantholora (E - male; F - female), also from the Yucatán Peninsula, Mexico. The three taxa are 812 the smallest members of the genus Amazona. 

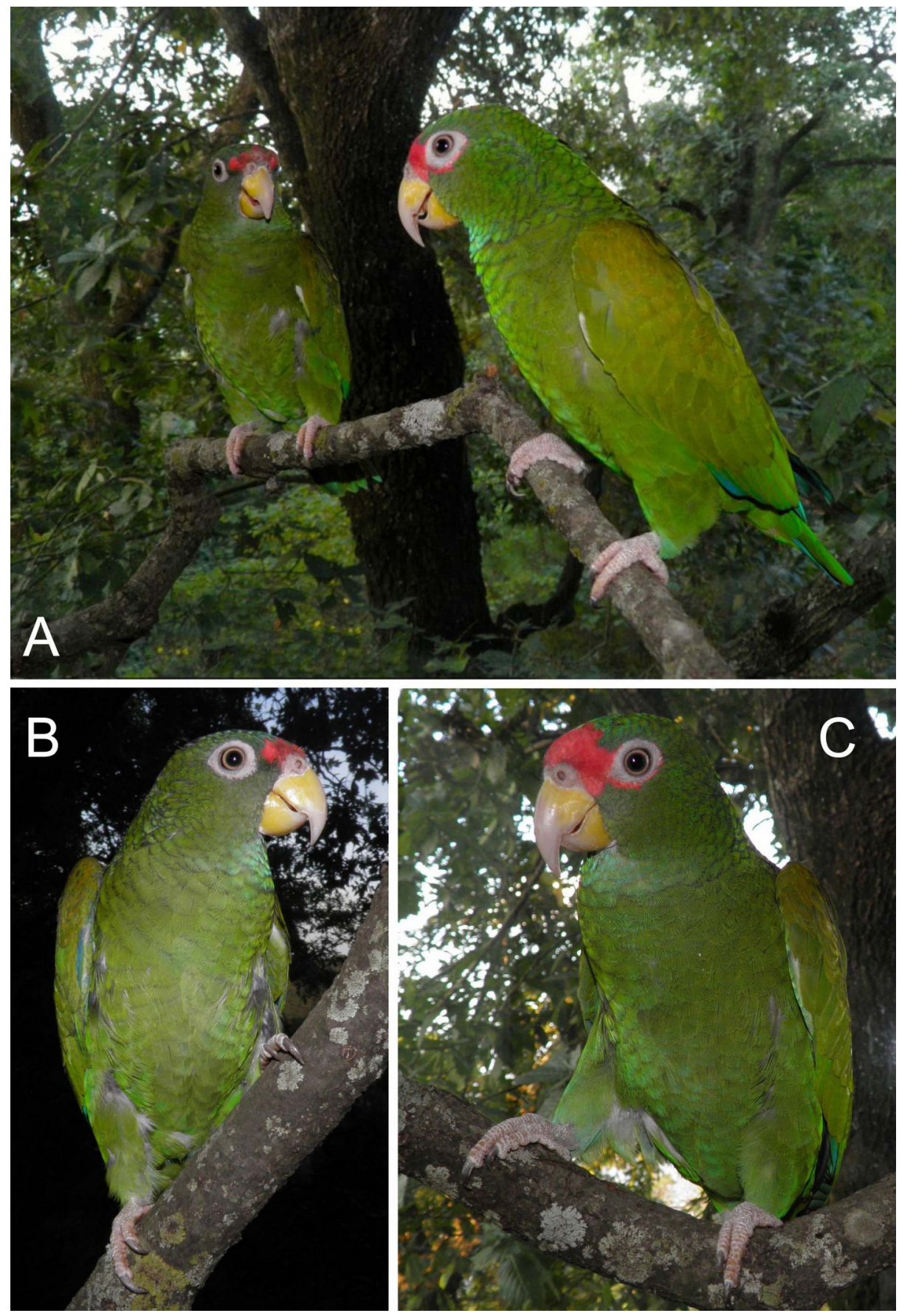

813 Fig. 4. Photograph of the male holotype (panel $\mathrm{C}$ and panel $\mathrm{A}$ - individual on the right) and 814 female paratype (panel B and panel A - individual on the left) of the new Amazona. 


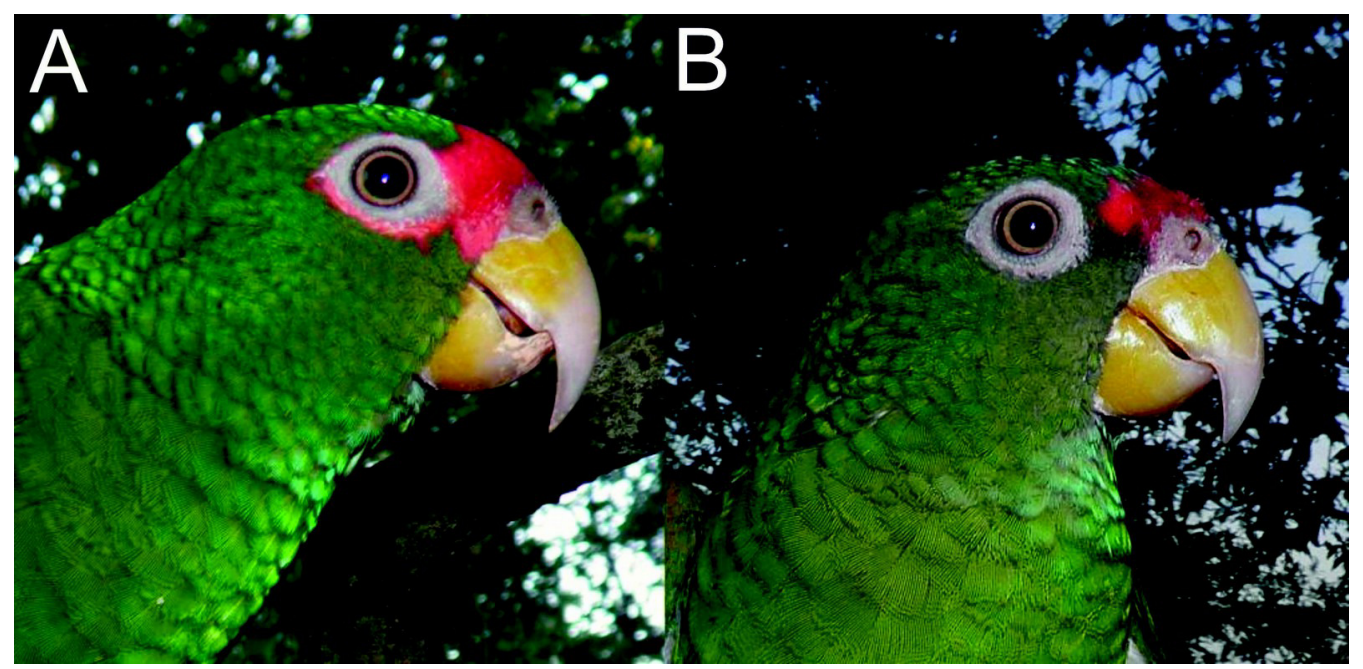

815 Fig. 5. Photographs of the head of male holotype (A) and female paratype (B) of the new 816 Amazona. 


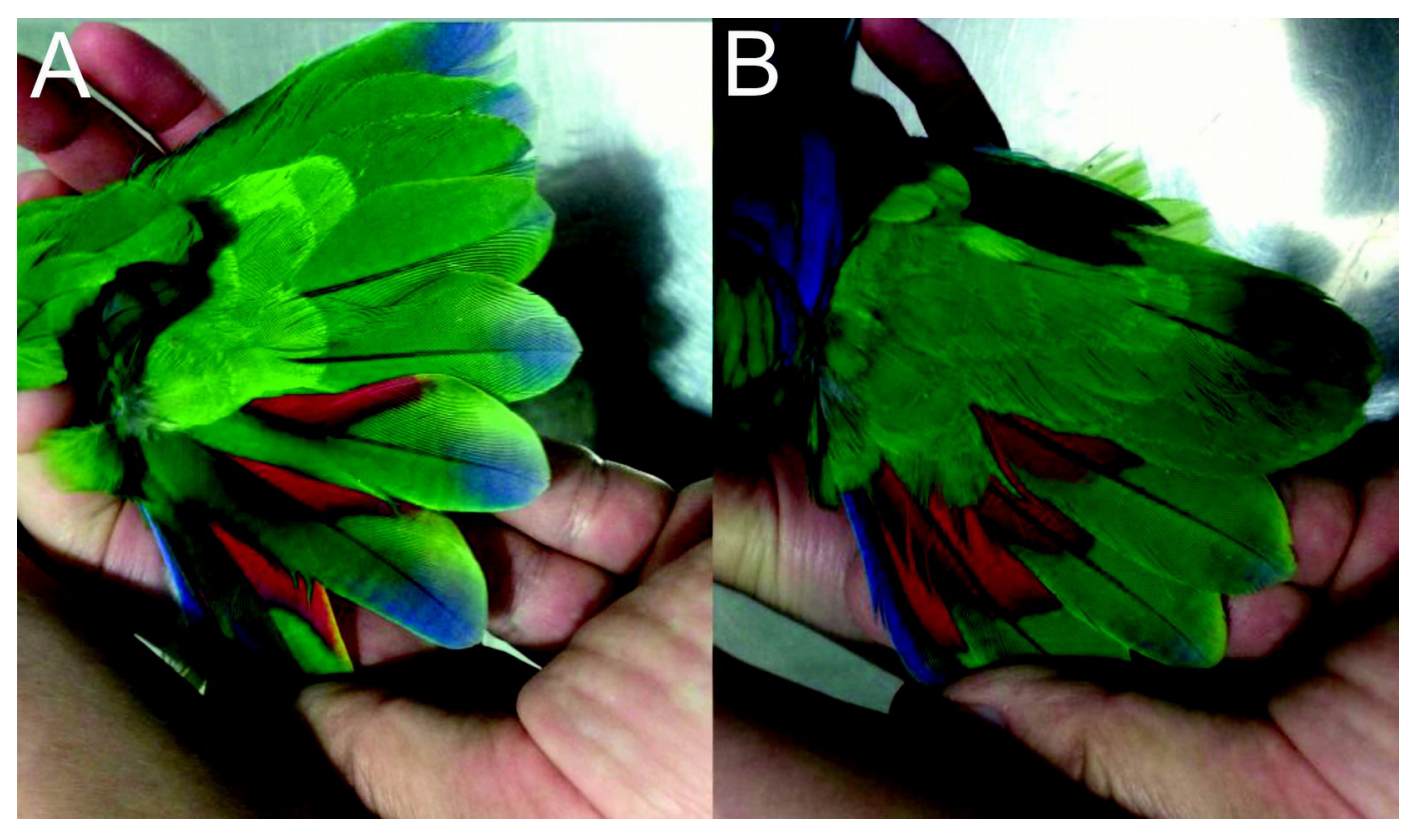

817 Fig. 6. Open tails showing colored bands of male holotype (A) and female paratype (B) of the 818 new Amazona. 

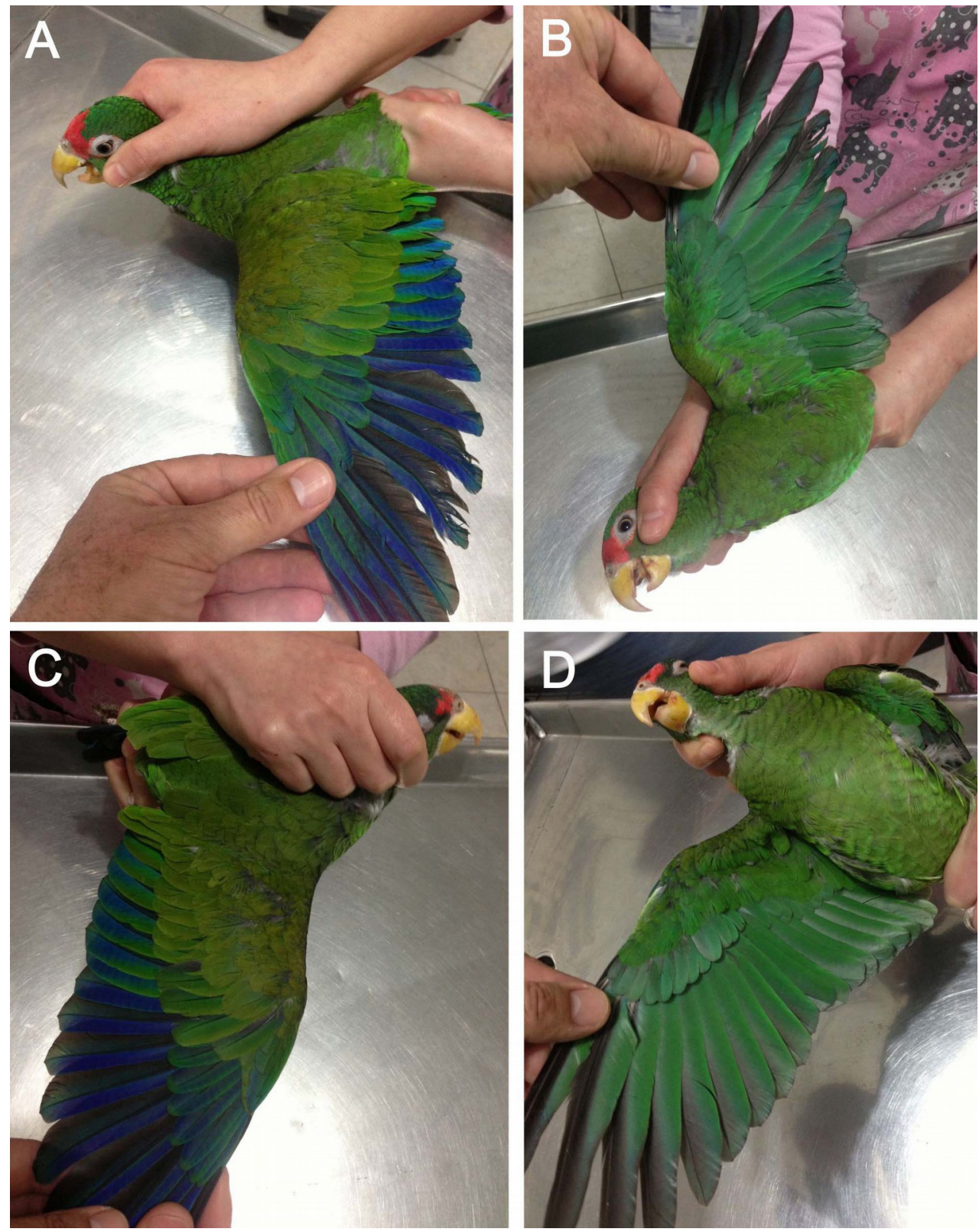

819 Fig. 7. Open upper (A) and underside of wing (B) of male holotype as well as open upper (C) and 820 underside of wing (D) of female paratype of the new Amazona. 


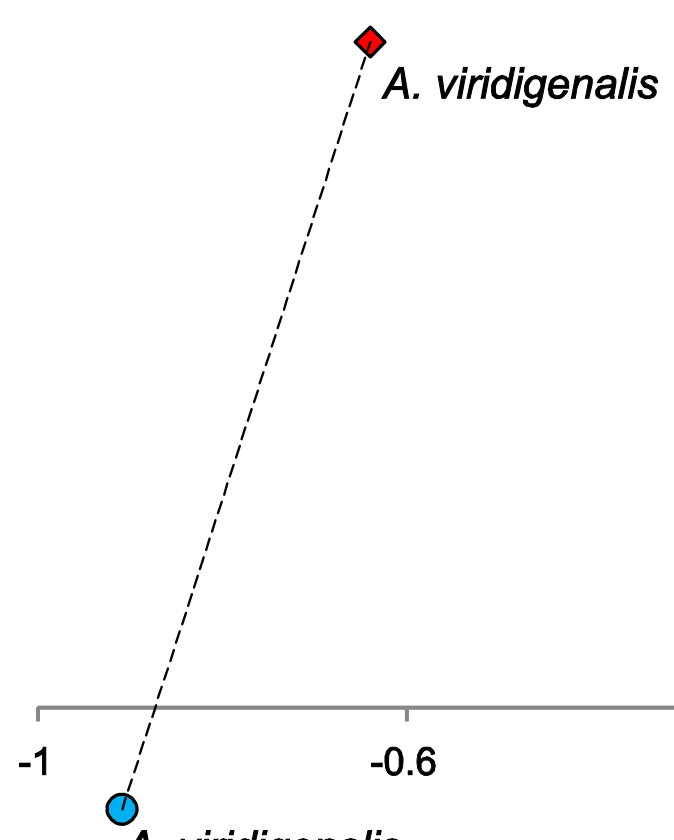

A. viridigenalis

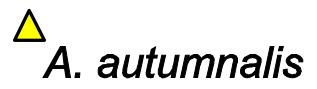

New Amazona $O$

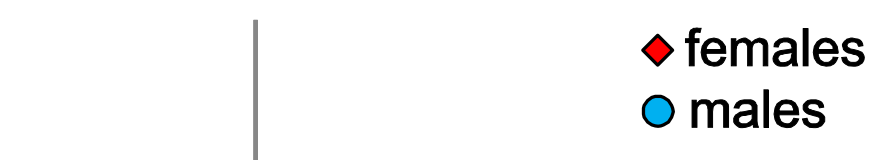

0.26

A. a. saltuensis

A. a. saltuensis 0.06

0.16

New Amazona,

$-0.2$
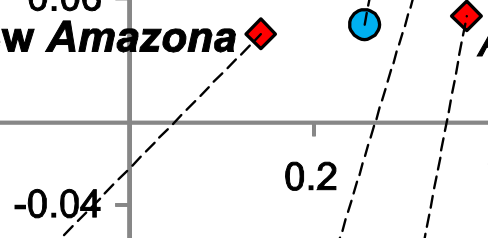

A. xantholora

A. a. albifrons

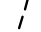

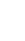




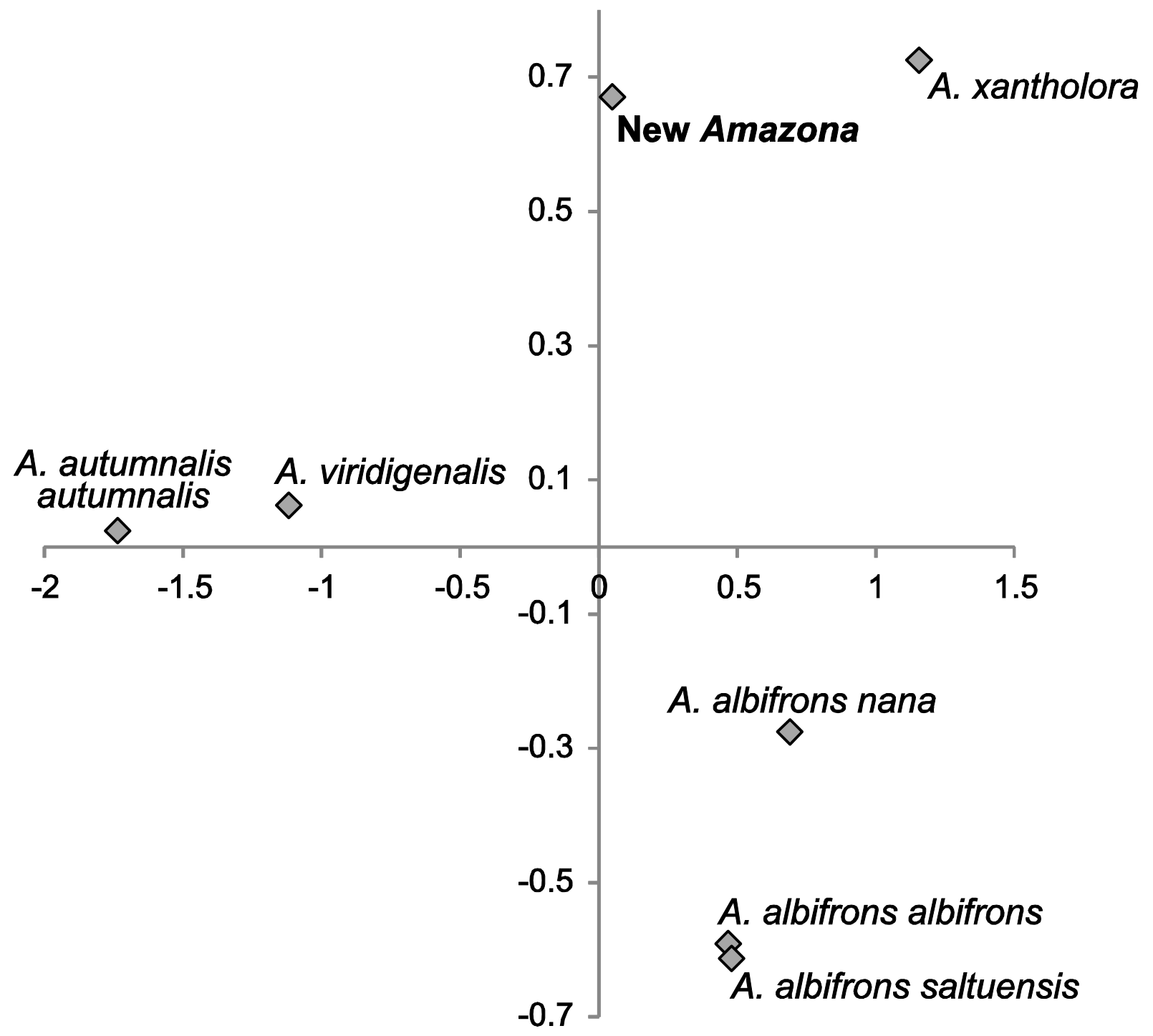

826 Fig. 9. The plot of the two-factor coordinates from Principal Component Analysis for Amazona 827 species displaying red head feathers from Mexico and Mesoamerica based on all morphometric 828 features. 


\section{Distance}
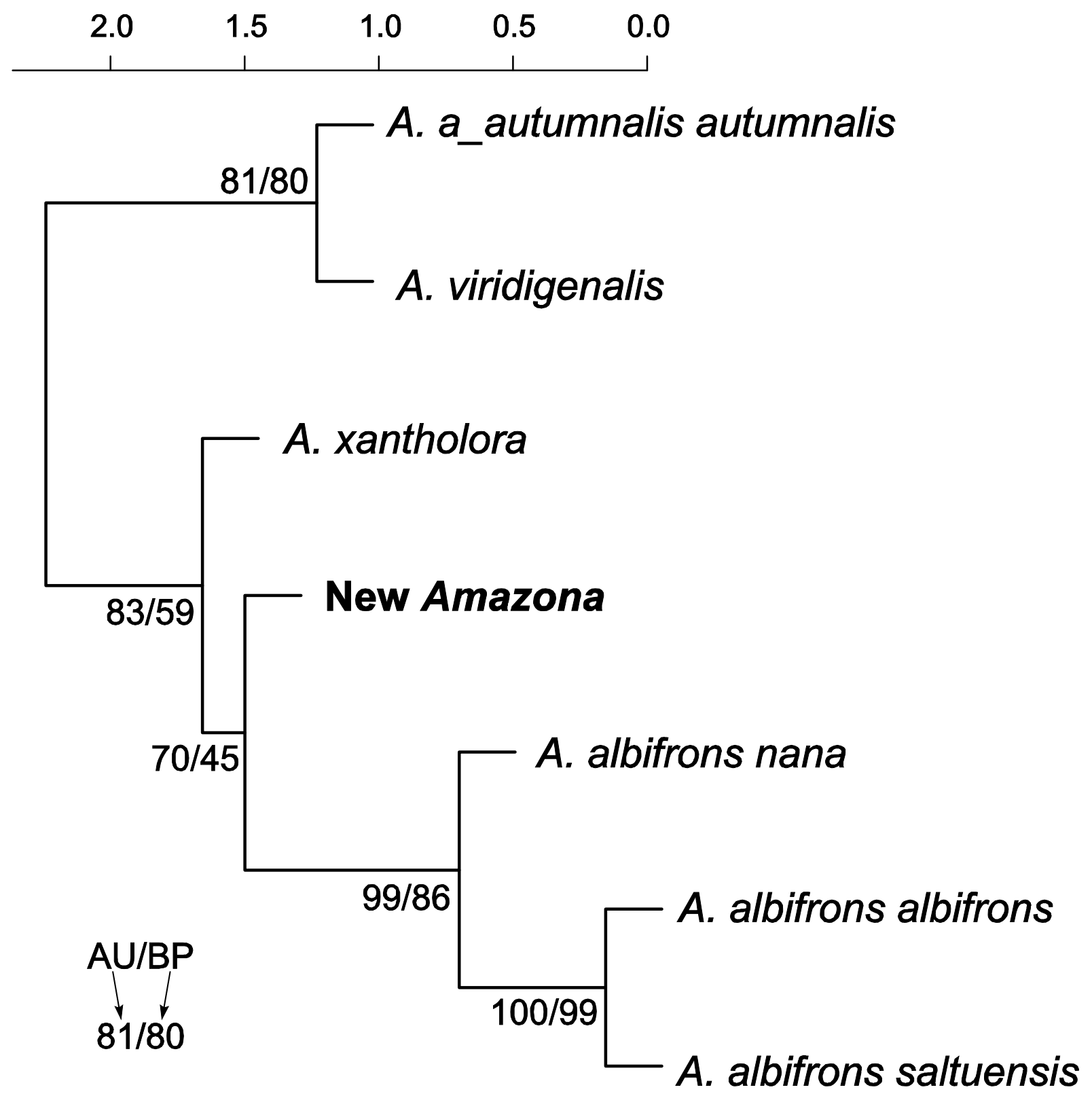

829 Fig. 10. UPGMA dendrogram clustering parrot taxa according to five metric parameters (body 830 weight and length, length of wing chord, tail and exposed culmen) and six morphological discrete 831 characters (body weight, total length, length of wing chord, tail length, exposed culmen). 832 Numbers at nodes correspond to p-values expressed as percentages calculated using 833 approximately unbiased test (AU) and bootstrap resampling (BP), respectively. 

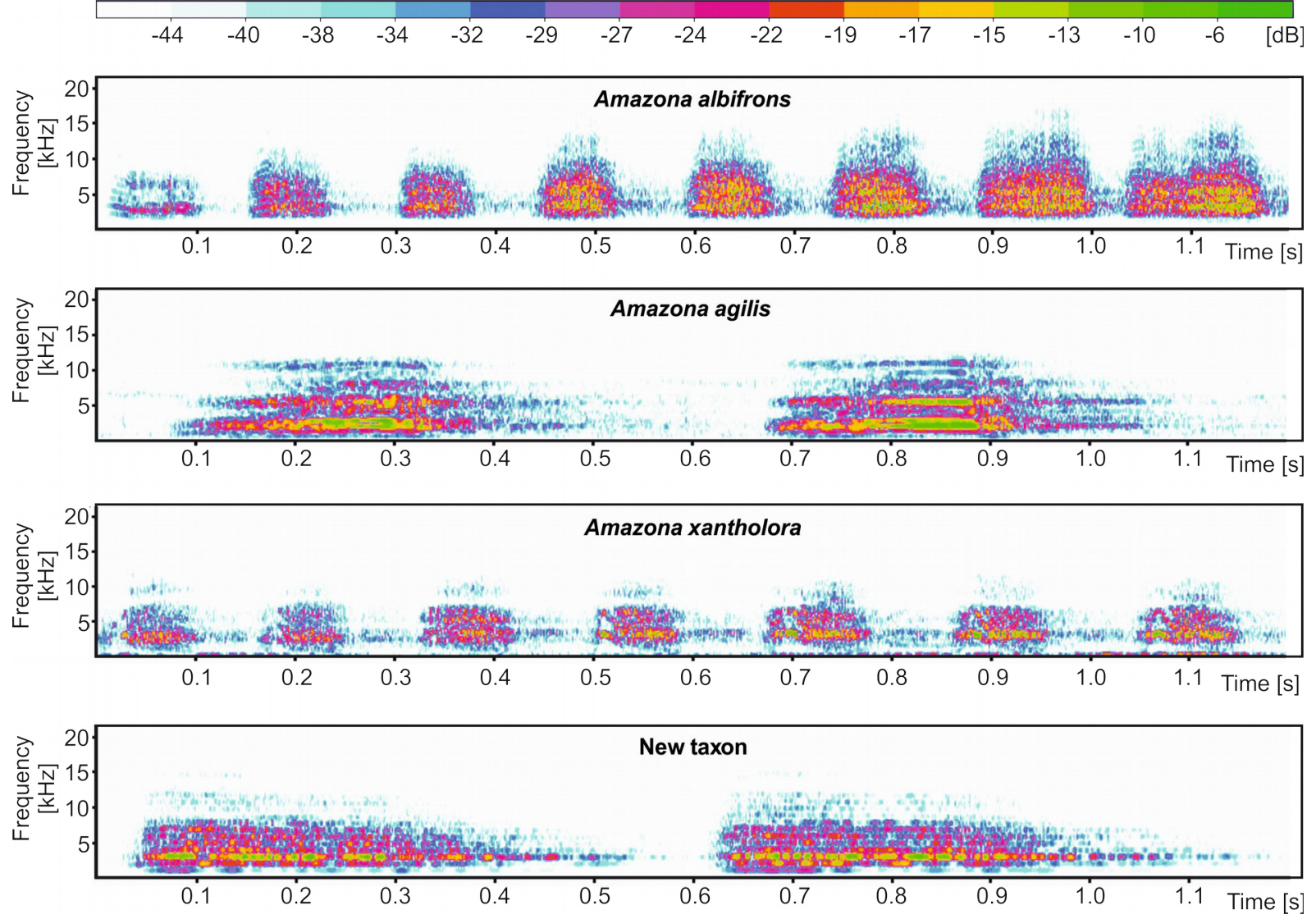

834 Fig. 11. Comparison of example sonogram for the new taxon with two other Amazona parrots 835 from Central America and closely related Amazona agilis from the Greater Antilles. 


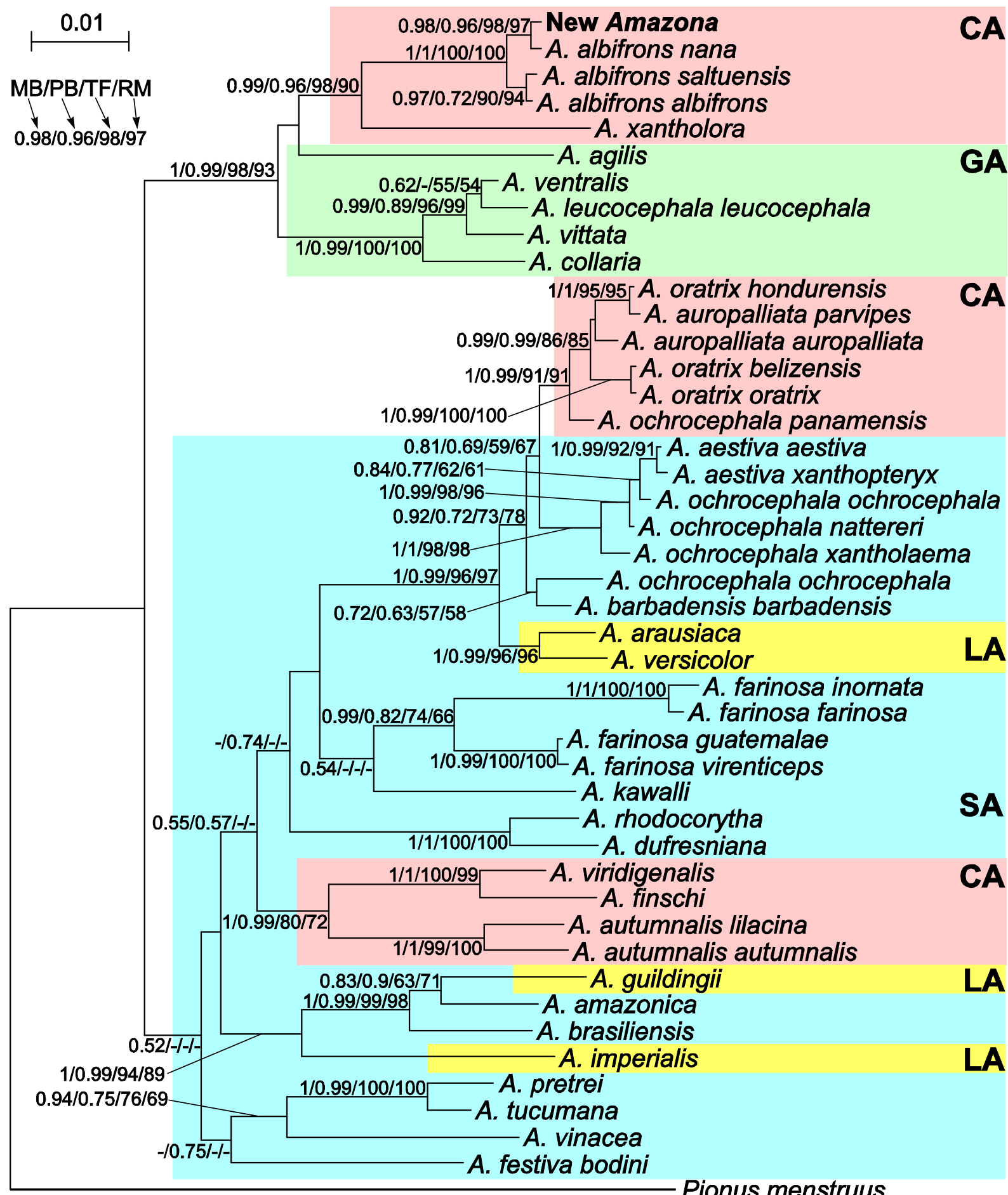

836 Fig. 12. MrBayes maximum clade credibility tree for the concatenated alignment of genes for 837 COI, 12S and 16S rRNA sequences from Amazona taxa and Pionus menstruus species (as 838 outgroup). Numbers at nodes, in the order shown, correspond to: posterior probabilities estimated 839 in MrBayes (MB) and PhyloBayes (PB), and bootstrap support values obtained in TreeFinder 840 (TF) and RAxML (RM). Values of the posterior probabilities and bootstrap percentages lower 841 than 0.50 and $50 \%$, respectively, were omitted or indicated by a dash "-". CA - Central America 842 parrots; GA - Greater Antillean parrots; LA - Lesser Antillean parrots; SA -South America 843 parrots. 


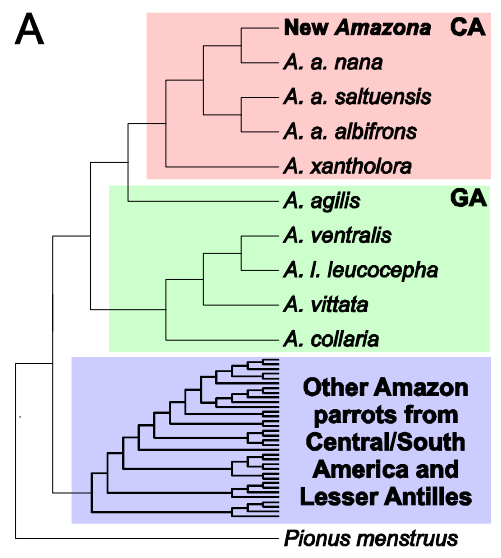

The best tree

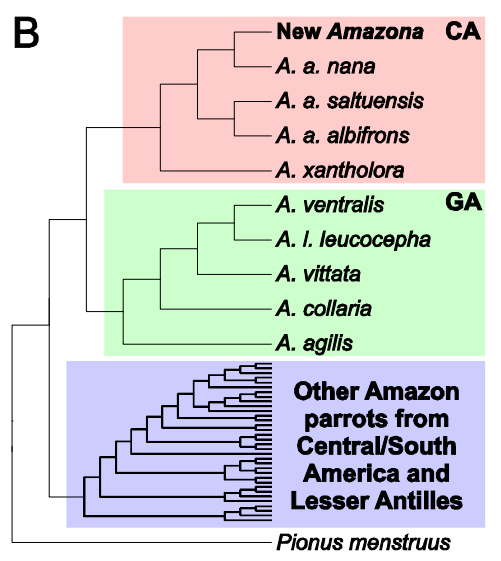

$\mathrm{AU}=0.491 ; \mathrm{SH}=0.780 ; \mathrm{WSH}=0.765$

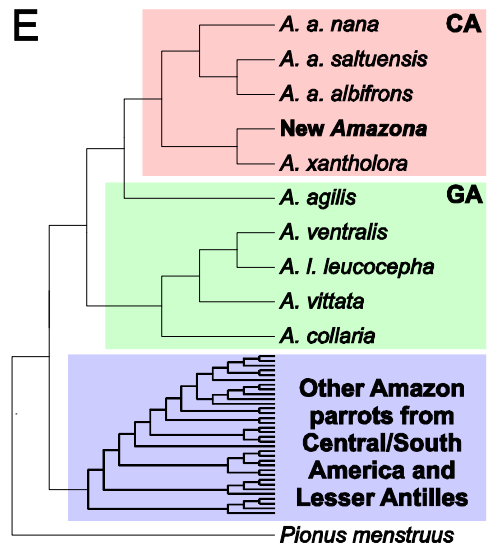

$\mathrm{AU}=0.001 ; \mathrm{SH}=0.005 ; \mathrm{WSH}=0.008$

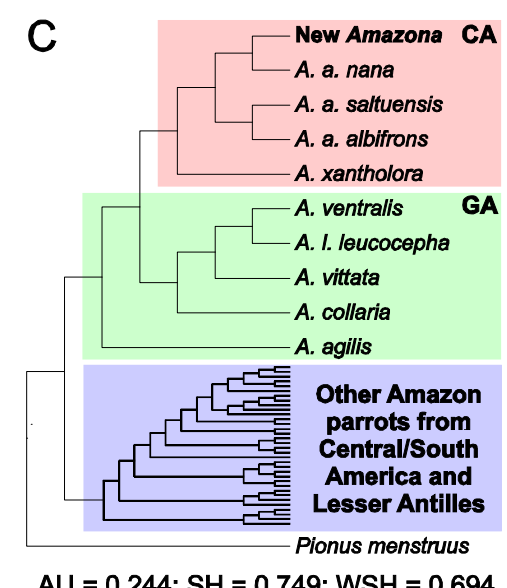

$\mathbf{F}$

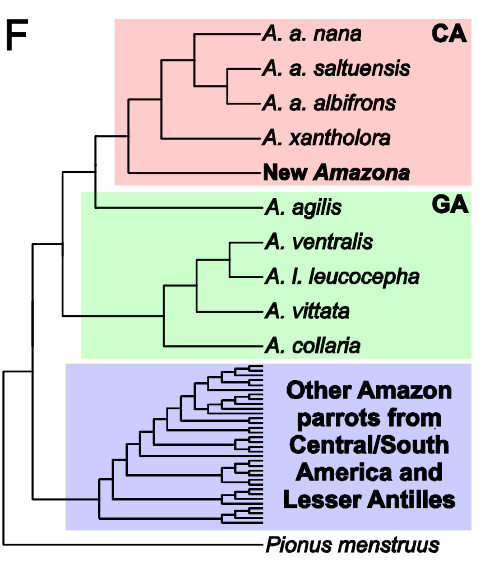

$\mathrm{AU}=0.001 ; \mathrm{SH}=0.005 ; \mathrm{WSH}=0.007$

844 Fig. 13. Alternative tree topologies assuming different placement of A. agilis (B and C) and the 845 new Amazona (D, E, F) in comparison to the best found tree (A). P-values of approximately 846 unbiased (AU), Shimodaira-Hasegawa (SH) and weighted Shimodaira-Hasegawa (wSH) tests 847 were shown. Only trees $\mathrm{E}$ and $\mathrm{F}$ are significantly worse than the best tree, whereas B, C and D 848 cannot be rejected. SA -South America parrots; GA - Greater Antillean parrots; CA - Central 849 America parrots. 


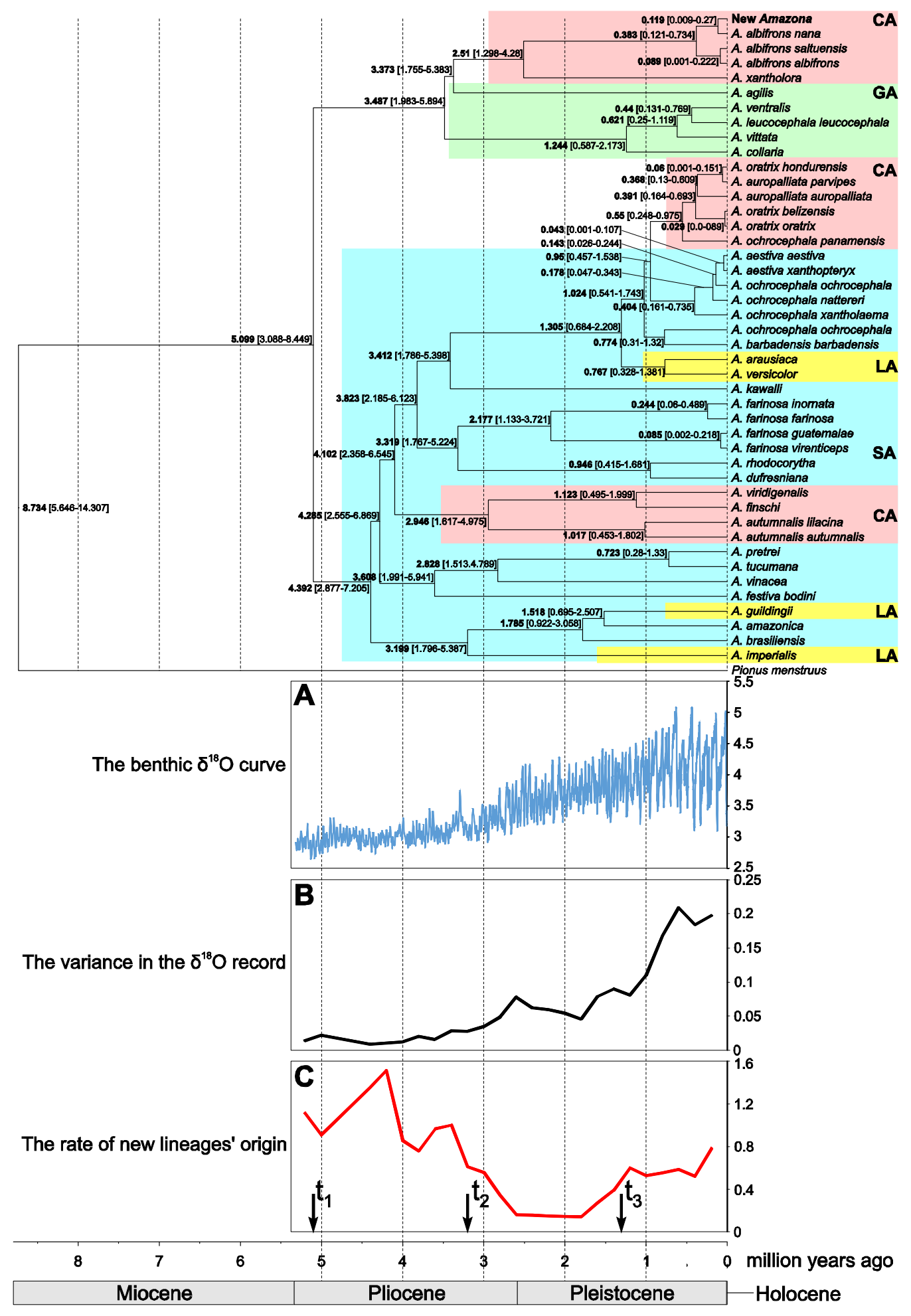

850 Fig. 14. Maximum clade credibility tree obtained in Beast for the concatenated alignment of 851 genes for COI, 12S and 16S rRNA sequences from selected Amazona taxa and Pionus menstruus 852 species (as outgroup). Mean (in bold) ages as well as the $95 \%$ highest posterior density 853 distributions (in parenthesis) are shown for particular nodes. CA - Central America parrots; GA 854 Greater Antillean parrots; LA - Lesser Antillean parrots; SA -South America parrots. The tree 855 was compared with benthic $\delta^{18} \mathrm{O}$ curve according to Lisiecki \& Raymo (2005) (A), the variance 856 in the $\delta^{18} \mathrm{O}$ records $(\mathrm{B})$ and the rate of new lineages' origin (C). Arrows $\mathrm{t}_{1}, \mathrm{t}_{2}$ and $\mathrm{t}_{3}$ in $\mathrm{C}$ indicate 
857 times in which the speciation rate shifts to a new rate according to the best-fitting yule4rate 858 model.

\section{References}

860 Athreya R. 2006. A new species of Liocichla (Aves: Timaliidae) from Eaglenest Wildlife Sanctuary, Arunachal Pradesh, India. Indian Birds 2:82-94.

Barrowclough GF, Cracraft J, Klicka J, and Zink RM. 2016. How Many Kinds of Birds Are There and Why Does It Matter? PLoS One 11:e0166307. 10.1371/journal.pone.0166307

Böhme W, and Ziegler T. 1997. Varanus melinus sp. n., ein neuer Waran aus der V. indicusGruppe von den Molukken, Indonesien [Varanus melinus sp. n., a new monitor lizard of the V. indicus group from Moluccas, Indonesia.]. Herpetofauna (Weinstadt) 19:2634.

Bond J. 1963. Derivation of the Antillean avifauna. Proc Acad Nat Sci Phila 115:79-98.

Bouckaert R, Heled J, Kuhnert D, Vaughan T, Wu CH, Xie D, Suchard MA, Rambaut A, and Drummond AJ. 2014. BEAST 2: a software platform for Bayesian evolutionary analysis. PLoS Comput Biol 10:e1003537. 10.1371/journal.pcbi.1003537

Brumfield RT, Jernigan RW, McDonald DB, and Braun MJ. 2001. Evolutionary implications of divergent clines in an avian (Manacus : Aves) hybrid zone. Evolution 55:2070-2087.

Caparroz R, and Pacheco JF. 2006. A homonymy in Psittacidae: new name for Salvatoria Miranda-Ribeiro. Revista Brasileira de Ornitologia 14:174-175.

Carling MD, and Brumfield RT. 2008. Haldane's Rule in an Avian System: Using Cline Theory and Divergence Population Genetics to Test for Differential Introgression of Mitochondrial, Autosomal, and Sex-Linked Loci across the Passerina Bunting Hybrid Zone. Evolution 62:2600-2615. 10.1111/j.1558-5646.2008.00477.x

Clements JF, Schulenberg TS, Iliff MJ, Roberson D, Fredericks TA, Sullivan BL, and Wood CL. 2016. The eBird/Clements checklist of birds of the world: v2016. http://wwwbirdscornelledu/clementschecklist/download/.

Collar NJ, and Pittman AJ. 1996. Amazona kawalli is a valid name for a valid species. Bulletin of the British Ornithologists' Club 116:256-265.

Darrieu CA. 1983. Revision de las razas geograficas de Amazona aestiva (Linne) (Aves, Psittacidae). Neotropica (La Plata) 29:3-10.

Donegan TM. 2008. New species and subspecies descriptions do not and should not always require a dead type specimen. Zootaxa 1761:37-48.

Drummond AJ, Suchard MA, Xie D, and Rambaut A. 2012. Bayesian phylogenetics with BEAUti and the BEAST 1.7. Mol Biol Evol 29:1969-1973. 10.1093/molbev/mss075

Duarte JMB, and Caparroz R. 1995. Cytotaxonomic analysis of Brazilian species of the genus Amazona (Psittacidae, Aves) and confirmation of the genus Salvatoria (Ribeiro, 1920). Brazilian Journal of Genetics 18:623-628.

Dubois A. 2009. Endangered species and endangered knowledge. Zootaxa 2201:26-29.

Dubois A, and Nemésio A. 2007. Does nomeclatural availability of nomina of new species or subspecies require the deposition of vouchers in the collections? Zootaxa 1409:1-22.

Eberhard JR, and Bermingham E. 2004. Phylogeny and biogeography of the Amazona ochrocephala (Aves: Psittacidae) complex. Auk 121:318-332.

Eberhard JR, and Wright TF. 2016. Rearrangement and evolution of mitochondrial genomes in parrots. Mol Phylogenet Evol 94:34-46. 10.1016/j.ympev.2015.08.011 
902 Edwards SV, Kingan SB, Calkins JD, Balakrishnan CN, Jennings WB, Swanson WJ, and 903 Sorenson MD. 2005. Speciation in birds: genes, geography, and sexual selection. Proc 904 905

906 907 908

909

910

911

912

913

914

915

916

917

918

919

920

921

922

923

924

925

926

927

928

929

930

931

932

933

934

935

936

937

938

939

940

941

942

943

944

945

946

947

948

949 Natl Acad Sci U S A 102 Suppl 1:6550-6557. 10.1073/pnas.0501846102

Forshaw JM. 1973. Parrots of the World. Melbourne: Lansdowne Press.

Fridolfsson A-K, and Ellegren H. 1999. A simple and universal method for molecular sexing of non-ratite birds. Journal of Avian Biology 30:116-121.

Funk DJ, and Omland KE. 2003. Species-level paraphyly and polyphyly: Frequency, causes, and consequences, with insights from animal mitochondrial DNA. Annual Review of Ecology Evolution and Systematics 34:397-423. 10.1146/annurev.ecolsys.34.011802.132421

Gentile G, and Snell H. 2009. Conolophus marthae sp. nov. (Squamata, Iguanidae), a new species of land iguana from the Galapagos archipelago. Zootaxa 2201:1-10.

Gill F, and Donsker D. 2017. IOC World Bird List (v 7.1). doi : 1014344/IOCML71. doi : 10.14344/IOC.ML.5.2.

Gómez Garza MA. 2014. Loros de México: Historia Natural. MAPorrúa. México: Secretaría de Medio Ambiente y Recursos Naturales (SEMARNAT), Procuraduría Federal de Protección al Ambiente (PROFEPA).

Grantsau R, and Camargo HFdA. 1989. Nove espécie de Amazona (Aves, Psittacidae). Revista Brasileira de Biologia 49:1017-1020.

Haldane JBS. 1922. Sex Ratio and Unisexual Sterility in Hybrid Animals. Journal of Genetics Cambridge 12:pp. 101-109.

Hansen J, Sato M, Russell G, and Kharecha P. 2013. Climate sensitivity, sea level and atmospheric carbon dioxide. Philosophical Transactions of the Royal Society aMathematical Physical and Engineering Sciences 371:20120294. 10.1098/Rsta.2012.0294

Helbig AJ, Seibold I, Kocum A, Liebers D, Irwin J, Bergmanis U, Meyburg BU, Scheller W, Stubbe M, and Bensch S. 2005. Genetic differentiation and hybridization between greater and lesser spotted eagles (Accipitriformes:Aquila clanga, A. pomarina). Journal of Ornithology 146:226-234. 10.1007/s10336-005-0083-8

Herminio Plasencia-Vazquez A, and Escalona-Segura G. 2014. Relative Abundance of Parrots throughout the Yucatan Peninsula: Implications for their Conservation. Wilson Journal of Ornithology 126:759-766.

Hudson RR, and Turelli M. 2003. Stochasticity overrules the "three-times rule": Genetic drift, genetic draft, and coalescence times for nuclear loci versus mitochondrial DNA. Evolution 57:182-190.

Huelsenbeck JP, Larget B, and Alfaro ME. 2004. Bayesian phylogenetic model selection using reversible jump Markov chain Monte Carlo. Mol Biol Evol 21:1123-1133. $10.1093 / \mathrm{molbev} / \mathrm{msh} 123$

Jobb G, von Haeseler A, and Strimmer K. 2004. TREEFINDER: a powerful graphical analysis environment for molecular phylogenetics. BMC Evol Biol 4:18. 10.1186/1471-21484-18

Jones T, Ehardt CL, Butynski TM, Davenport TR, Mpunga NE, Machaga SJ, and De Luca DW. 2005. The highland mangabey Lophocebus kipunji: a new species of African monkey. Science 308:1161-1164. 10.1126/science.1109191

Juniper T, and Parr M. 1998. Parrots: A Guide to the Parrots of the World. London: Yale University Press.

Lack D. 1976. Island biology, illustrated by the land birds of Jamaica.: Berkeley: Univ. Calif. Press. 
950

951

952

953

954

955

956

957

958

959

960

961

962

963

964

965

966

967

968

969

970

971

972

973

974

975

976

977

978

979

980

981

982

983

984

985

986

987

988

989

990

991

992

993

994

995

996

Lanfear R, Calcott B, Ho SY, and Guindon S. 2012. Partitionfinder: combined selection of partitioning schemes and substitution models for phylogenetic analyses. Mol Biol Evol 29:1695-1701. 10.1093/molbev/mss020

Lantermann W. 1997. Verbreitung und Evolution der Psittacidenfauna auf den ozeanischen Inseln der Karibik. Papageienkunde 1:263-278.

Lartillot N, Rodrigue N, Stubbs D, and Richer J. 2013. PhyloBayes MPI: phylogenetic reconstruction with infinite mixtures of profiles in a parallel environment. Syst Biol 62:611-615. 10.1093/sysbio/syt022

Lerner H, Christidis L, Gamauf A, Griffiths C, Haring E, Huddleston CJ, Kabra S, Kocum A, Krosby M, Kvaloy K, Mindell D, Rasmussen P, Rov N, Wadleigh R, Wink M, and Gjershaug J0. 2017. Phylogeny and new taxonomy of the Booted Eagles (Accipitriformes: Aquilinae). Zootaxa 4216:301-320. 10.11646/zootaxa.4216.4.1

Lesson RP. 1831. Traté d' Ornithologie, ou Tableau Méthodique des Ondres, Sous-Ondres, Familles, Tribus, Genres, Sous-Genres et Races d'Oiseaux. Paris: Impremerie de F.G. Levraut.

Lisiecki LE, and Raymo ME. 2005. A Pliocene-Pleistocene stack of 57 globally distributed benthic $\delta 180$ records. Paleoceanography 20:n/a-n/a. 10.1029/2004pa001071

Lousada S. 1989. Amazona auropalliata caribaea: a new subspecies of parrot from the Bay Islands, northern Honduras. Bulletin of the British Ornithologists' Club 109:232-235.

Lousada SA, and Howell SNG. 1997. Amazona oratrix hondurensis: a new subspecies of parrot from the Sula Valley of northern Honduras. Bulletin of the British Ornithologists' Club 117:205-209.

Martuscelli P, and Yamashita C. 1997. Rediscovery of the white-cheeked parrot Amazona kawalli (Grantsau and Camargo 1989), with notes on its ecology, distribution, and taxonomy. Ararajuba 5:97-113.

Medina-Garcia A, Araya-Salas M, and Wright TF. 2015. Does vocal learning accelerate acoustic diversification? Evolution of contact calls in Neotropical parrots. J Evol Biol 28:1782-1792. 10.1111/jeb.12694

Montes C, Cardona A, Jaramillo C, Pardo A, Silva JC, Valencia V, Ayala C, Perez-Angel LC, Rodriguez-Parra LA, Ramirez V, and Nino H. 2015. Middle Miocene closure of the Central American Seaway. Science 348:226-229. 10.1126/science.aaa2815

Nee S. 2001. Inferring speciation rates from phylogenies. Evolution 55:661-668. Doi 10.1554/0014-3820(2001)055[0661:Isrfp]2.0.Co;2

Nemesio A. 2009. Nomenclatural availability of nomina of new species should always require the deposition of preserved specimens in collections: a rebuttal to Donegan (2008). Zootaxa 2045:1-14.

Nittinger F, Gamauf A, Pinsker W, Wink M, and Haring E. 2007. Phylogeography and population structure of the saker falcon (Falco cherrug) and the influence of hybridization: mitochondrial and microsatellite data. Mol Ecol 16:1497-1517. 10.1111/j.1365-294X.2007.03245.x

Ottens-Wainright P, Halanych KM, Eberhard JR, Burke RI, Wiley JW, Gnam RS, and Galvez Aquilera X. 2004. Independent geographic origins of the genus Amazona in the West Indies. Journal of Caribbean Ornithology 17:23-49.

Päckert M, Martens J, Wink M, Feigl A, and Tietze DT. 2012. Molecular phylogeny of Old World swifts (Aves: Apodiformes, Apodidae, Apus and Tachymarptis) based on mitochondrial and nuclear markers. Mol Phylogenet Evol 63:606-616. 10.1016/j.ympev.2012.02.002 
997 Pettingill OS. 1970. Ornithology in laboratory and field. 4th edition. Minneapolis, MN: 998 Burgess Publishing Co.

999 Polaszek A, Grubb P, Groves C, Erhardt CL, and Butynski TM. 2005. What constitutes a 1000 proper description? Response. Science 309:2164-2166.

1001 Pybus OG, and Harvey PH. 2000. Testing macro-evolutionary models using incomplete

1002 molecular phylogenies. Proceedings of the Royal Society B-Biological Sciences 1003 267:2267-2272.

1004 R_Core_Team. 2015. R: A language and environment for statistical computing.: R Foundation 1005

1006

1007

1008

1009

1010

1011

1012

1013

1014

1015

1016

1017

1018

1019

1020

1021

1022

1023

1024

1025

1026

1027

1028

1029

1030

1031

1032

1033

1034

1035

1036

1037

1038

1039

1040

1041

1042 for Statistical Computing, Vienna, Austria. URL https://www.R-project.org/.

Rabosky DL. 2006a. LASER: A Maximum Likelihood Toolkit for Detecting Temporal Shifts in Diversification Rates From Molecular Phylogenies. Evolutionary Bioinformatics 2:247-250.

Rabosky DL. 2006b. Likelihood methods for detecting temporal shifts in diversification rates. Evolution 60:1152-1164.

Rabosky DL, and Lovette IJ. 2008. Explosive evolutionary radiations: Decreasing speciation or increasing extinction through time? Evolution 62:1866-1875. 10.1111/j.15585646.2008.00409.x

Rambaut A. 2012. FigTree v1.4.0. Available from: http://treebioedacuk/software/figtree/.

Rambaut A, Suchard MA, Xie D, and Drummond AJ. 2014. Tracer v1.6. Available from http://beastbioedacuk/Tracer.

Reynolds MBJ, and Hayes WK. 2009. Conservation taxonomy of the cuban parrot (Amazona leucocephala): variation in morphology and plumage. Journal of Caribbean Ornithology 22:1-18.

Rheindt FE, and Edwards SV. 2011. Genetic Introgression: An Integral but Neglected Component of Speciation in Birds. Auk 128:620-632. 10.1525/auk.2011.128.4.620

Ribas CC, Aleixo A, Nogueira AC, Miyaki CY, and Cracraft J. 2012. A palaeobiogeographic model for biotic diversification within Amazonia over the past three million years. Proc Biol Sci 279:681-689. 10.1098/rspb.2011.1120

Ribas CC, Tavares ES, Yoshihara C, and Miyaki CY. 2007. Phylogeny and biogeography of yellow-headed and blue-fronted parrots (Amazona ochrocephala and Amazona aestiva) with special reference to the South American taxa. Ibis 149:564-574.

Ribot RF, Buchanan KL, Endler JA, Joseph L, Bennett AT, and Berg ML. 2012. Learned vocal variation is associated with abrupt cryptic genetic change in a parrot species complex. PLoS One 7:e50484. 10.1371/journal.pone.0050484

Ronquist F, Teslenko M, van der Mark P, Ayres DL, Darling A, Hohna S, Larget B, Liu L, Suchard MA, and Huelsenbeck JP. 2012. MrBayes 3.2: efficient Bayesian phylogenetic inference and model choice across a large model space. Syst Biol 61:539-542. 10.1093 /sysbio/sys029

Ross HA. 2014. The incidence of species-level paraphyly in animals: A re-assessment. Mol Phylogenet Evol 76:10-17. 10.1016/j.ympev.2014.02.021

Rull V. 2011. Neotropical biodiversity: timing and potential drivers. Trends Ecol Evol 26:508513. 10.1016/j.tree.2011.05.011

Russello MA, and Amato G. 2004. A molecular phylogeny of Amazona: implications for Neotropical parrot biogeography, taxonomy, and conservation. Mol Phylogenet Evol 30:421-437.

1043 Ellegren H. 2001. Speciation, introgressive hybridization and nonlinear rate of 
1044

1045

1046

1047

1048

1049

1050

1051

1052

1053

1054

1055

1056

1057

1058

1059

1060

1061

1062

1063

1064

1065

1066

1067

1068

1069

1070

1071

1072

1073

1074

1075

1076

1077

1078

1079

1080

1081

1082

1083

1084

1085

1086

1087

1088

1089

1090

1091

molecular evolution in flycatchers. Mol Ecol 10:737-749. DOI $10.1046 / \mathrm{j} .1365$ 294x.2001.01208.x

Saetre GP, Borge T, Lindroos K, Haavie J, Sheldon BC, Primmer C, and Syvanen AC. 2003. Sex chromosome evolution and speciation in Ficedula flycatchers. Proceedings of the Royal Society B-Biological Sciences 270:53-59. 10.1098/rspb.2002.2204

Salinas-Melgoza A, and Wright TF. 2012. Evidence for Vocal Learning and Limited Dispersal as Dual Mechanisms for Dialect Maintenance in a Parrot. PLoS One 7:e48667. 10.1371/journal.pone.0048667.g001

Schodde R, Remsen JV, Schirtzinger EE, Joseph L, and Wright TF. 2013. Higher classification of New World parrots (Psittaciformes; Arinae), with diagnoses of tribes. Zootaxa 3691:591-596.

Schweizer M, Hertwig ST, Seehausen 0, and Ebach M. 2014. Diversity versus disparity and the role of ecological opportunity in a continental bird radiation. Journal of Biogeography 41:1301-1312. 10.1111/jbi.12293

Schweizer M, Seehausen 0, and Hertwig ST. 2011. Macroevolutionary patterns in the diversification of parrots: effects of climate change, geological events and key innovations. Journal of Biogeography 38:2176-2194. 10.1111/j.13652699.2011.02555.x

Shimodaira H. 2004. Approximately unbiased tests of regions using multistep-multiscale bootstrap resampling. Annals of Statistics 32:2616-2641. $10.1214 / 009053604000000823$

Shimodaira H, and Hasegawa M. 2001. CONSEL: for assessing the confidence of phylogenetic tree selection. Bioinformatics 17:1246-1247.

Silva T. 1991. Psittaculture: The Breeding, Rearing and Management of Parrots. Ontario: Silvio Mattacchione \& Co.

Silva T. 2014. Nová systematika amazonanu kubánskych. Nová Exota 5:6-8.

Silva T. 2015. Průvodce chovem Papoušků. Horka nad Moravou, Czech Republic: Nová Exota.

Smith EFG, Arctander P, Fjeldsa J, and Amir OG. 1991. A new species of shrike (Laniidae: Laniarius) from Somalia, verified by DNA sequence data from the only known individual. Ibis 133:227-235.

Snyder NFR, Wiley JW, and Kepler CB. 1987. The parrots of Luquillo: natural history and conservation of the Puerto Rican Parrot. Los Angeles, CA: West. Found. Vert. Zool.

Stamatakis A. 2014. RAxML version 8: a tool for phylogenetic analysis and post-analysis of large phylogenies. Bioinformatics 30:1312-1313. 10.1093/bioinformatics/btu033

StatSoft_Inc. 2011. STATISTICA (data analysis software system), version 10. www.statsoft.com.

Tamura K, Stecher G, Peterson D, Filipski A, and Kumar S. 2013. MEGA6: Molecular Evolutionary Genetics Analysis version 6.0. Mol Biol Evol 30:2725-2729. $10.1093 / \mathrm{molbev} / \mathrm{mst} 197$

Tchernichovski O, Nottebohm F, Ho CE, Bijan P, and Mitra PP. 2000. A procedure for an automated measurement of song similarity. Animal Behaviour 59:1167-1176.

Tegelstrom H, and Gelter HP. 1990. Haldane Rule and Sex Biased Gene Flow between 2 Hybridizing Flycatcher Species (Ficedula-Albicollis and F-Hypoleuca, Aves, Muscicapidae). Evolution 44:2012-2021. Doi 10.2307/2409611

Turelli M, and Orr HA. 1995. The dominance theory of Haldane's rule. Genetics 140:389-402. Urantowka AD, Mackiewicz P, and Strzala T. 2014. Phylogeny of Amazona barbadensis and the Yellow-headed Amazon complex (Aves: Psittacidae): a new look at South American parrot evolution. PLoS One 9:e97228. 10.1371/journal.pone.0097228 
1092 Vuilleumier F, LeCroy M, and Mayr E. 1992. New species of birds described from 1981 to 1093 1990. Bulletin of the British Ornithologists' Club 112A:267-309.

1094 Wakeham-Dawson A, Morris S, and Tubbs P. 2002. Type specimens: Dead or alive? Bulletin 1095 of Zoological Nomenclature 59:282-284.

1096 Wiley JW. 1991. Status and conservation of parrots and parakeets in the Greater Antilles, 1097 Bahama Islands, and Cayman Islands. Bird Conservation International 1:187-214.

1098 Wright TF, and Wilkinson GS. 2001. Population genetic structure and vocal dialects in an 1099 amazon parrot. Proc Biol Sci 268:609-616. 10.1098/rspb.2000.1403 